\title{
CONTRIBUCIÓN A LA ARQUEOLOGÍA DEL DELTA DEL PARANÁ: EL NIVEL ACERÁMICO DEL SITIO ISLA LECHIGUANAS1
}

\author{
Daniel Loponte ${ }^{1}$, Alejandro Acosta ${ }^{2}$ y Leonardo Mucciolo ${ }^{3}$ \\ ${ }^{1}$ CONICET-INAPL. 3 de Febrero 1378 C1426BJN, CABA. E-Mail: dloponte@inapl.gov.ar \\ ${ }^{2}$ CONICET-INAPL. 3 de Febrero 1378 C1426BJN, CABA. E-Mail: acosta@retina.ar \\ ${ }^{3}$ CONICET-INAPL. 3 de Febrero 1378 C1426BJN, CABA. E-Mail: leonardomucciolo@yahoo.com.ar
}

Presentado el: 10/12/2011 - Aceptado 06/05/2012

\begin{abstract}
Resumen
El sitio arqueológico Isla Lechiguanas 1 está ubicado en el sur de la isla homónima, en el Departamento de Gualeguay, al sur de la provincia de Entre Ríos, frente a la costa bonaerense. Se reconocieron dos unidades arqueológicas separadas por un conchero natural de Ampullariasp. que actuó como un sello estratigráfico entre ambos componentes. El nivel superior, datado en $408 \pm 30$ añosC14 AP, posee abundantes restos óseos y cerámica lisa e incisa, mientras que el nivel inferior no posee cerámica. En este nivel se recuperaron numerosos desechos de manufactura, instrumentos óseos y una importante colección faunística que es objeto de análisis en este trabajo. Dos fechados radiocarbónicos obtenidos en este nivel arrojaron una antigüedad de $2267 \pm 34$ años $C^{14}$ AP y $2296 \pm$ 34 años $C^{14} \mathrm{AP}$. La fauna recuperada está representada por los taxones actuales del área y del sector continental bonaerense, indicando el desarrollo de rangos amplios de captura y el establecimiento de una oferta similar a la actual a mediados del Holoceno tardío. Se discuten diversos aspectos relacionados con la tendencia regional del registro faunístico, las variaciones espacio-temporales de la subsistencia humana durante el Holoceno y la representación esqueletaria de algunas especies presentes en el depósito.
\end{abstract}

Palabras claves: Arqueología, Delta del Paraná, Islas Lechiguanas, Efecto reservorio.

\begin{abstract}
The archaeological site IslasLechiguanas 1 is located in the homonymous island, in the Department of Gualeguay, South of Entre Rios Province, in front of the fluvial coast of Buenos Aires Province. Two archaeological units were recognized, separated by a natural shell midden of Ampullaria sp. In the upper level, dated in $408 \pm 30^{14} \mathrm{CYBP}$, plentiful faunal remains and smooth and incised potterywere recovered. In the lower level, which is the main focus of this paper, there is no pottery, but it contains a large amount of faunal remains and bone tools. Two radiocarbon ages were obtained in this layer: $2267 \pm 34{ }^{14} \mathrm{C}$ YBP and $2296 \pm 34{ }^{14} \mathrm{C}$ YBP. The fauna recovered in this level is represented by current or recently extinct species of the local wetland and from the neighboring pampa plain, indicating the development of broad ranges of capture and the establishment of a similar offer to the current in the final period of the third millennium before present. We discuss some aspects related to the regional trend of archaeofaunal record and its spatial and temporal variations during the Late Holocene.
\end{abstract}

Keywords: Archaeology, Paraná Delta, Lechiguanas Island, Reservoir effect. 


\section{Introducción}

El sitio Isla Lechiguanas 1 (ILS1) se ubica en el sur de la isla homónima en el Departamento de Gualeguay, a los $33^{\circ} 44^{\prime} 28,30^{\prime \prime} \mathrm{S}$ y $59^{\circ} 13^{\prime} 40,50^{\prime \prime} \mathrm{O}$, a 300 mde la costa del río Paraná de la Palmas y a $17 \mathrm{~km}$ de la costa de la provincia de Buenos Aires a la altura de la ciudad de Baradero (ver figura 1). El depósito arqueológico se desarrolla en un albardón de 25 × $30 \mathrm{~m}$ aproximadamente. Fue inicialmente descripto y excavado por Caggiano $(1977,1984)$ durante los años 1972 y 1976, quien identificó dos niveles de ocupación humana bien diferenciados. El primero con cerámica y el segundo sin ella. Entre ambas, reconoció un conchero de Ampullaria sp., fechado en $2740 \pm 80$ y $2550 \pm 90$ años $C^{14}$ (Caggiano 1977).

Los análisis faunísticos de la colección recuperada en esas campañas fueron efectuados por Cione y Tonni (1978), quienes presentaron información relacionada con el número mínimo de individuos y marginalmente, algunos aspectos vinculados con la representación esqueletaria de determinadas especies. Esta colección está siendo reanalizada con diferentes criterios metodológicos, incluyendo el análisis de un gran número de pequeños especímenes óseos que aún poseen sedimentos adheridos que los inhabilitaba para su correcta determinación anatómica y sistemática.

El objetivo de este trabajo es efectuar un análisis preliminar del registro obtenido en las excavaciones efectuadas en la campaña del año 2011 en el nivel acerámico, con especial énfasis en su fauna, incluyendo algunos aspectos relacionados con la evolución de las estrategias de subsistencia en el área y el significado del contexto en términos generales dentro del marco arqueológico regional.

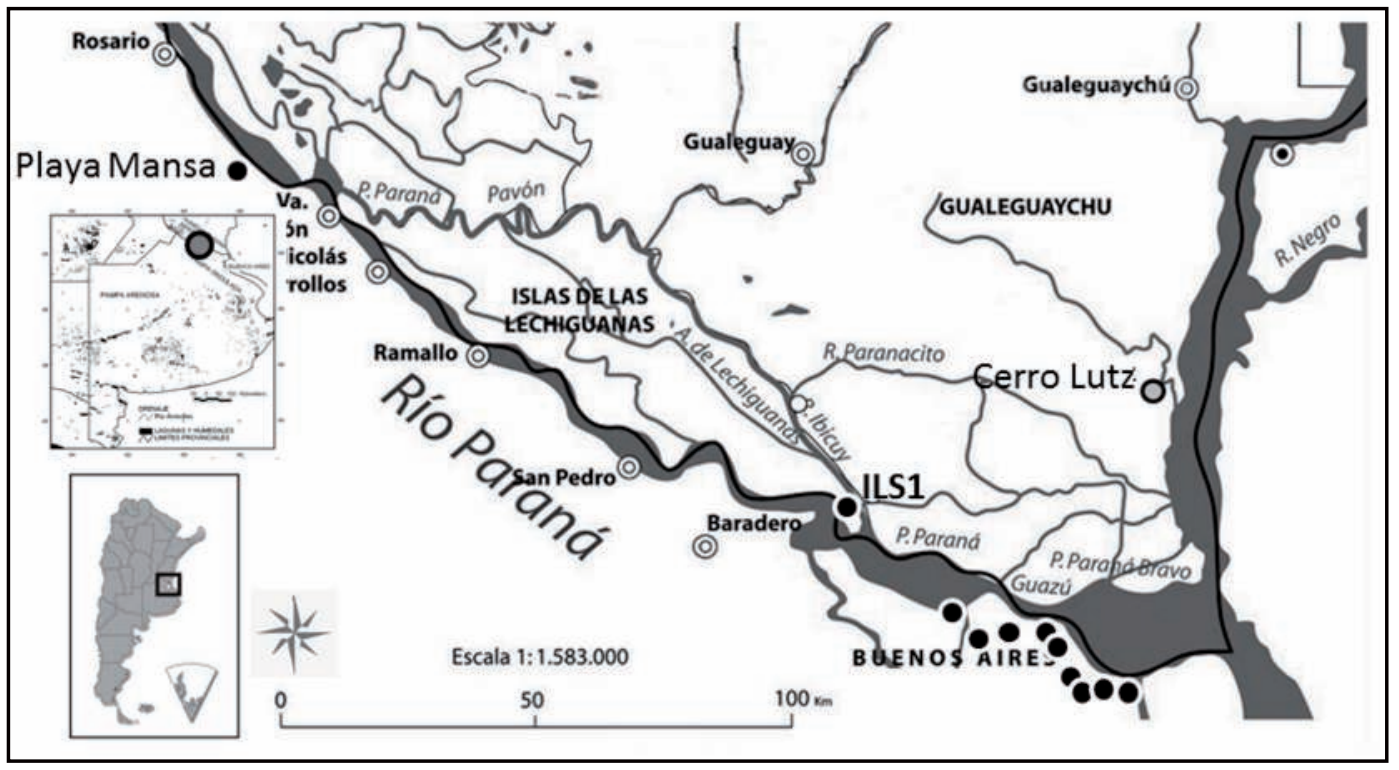

Figura 1. Localización del sitio Isla Lechiguanas 1 (ILS1). Los puntos en color negro sobre la costa de Buenos Aires al sur de la ciudad de Baradero corresponden a los sitios La Bellaca sitio 1, La Bellaca sitio 2; Garín, Anahí, Las Vizcacheras, Túmulode Campana sitio 2; Guazunambí, Arroyo Sarandí y Médanos de Escobar (cf. Loponte 2008; Acosta et al. 2011a). Sobre la margen derecha del río Uruguay, se ubica el sitio Cerro Lutz-CL- (Arrizurieta et al. 2010a) y al sur de la ciudad de Rosario, elsitio Playa Mansa (Sartori y Colasurdo 2011; Coll 2011). Respecto a la ubicación de los mismos en relación al mapa, esta es aproximada ${ }^{1}$. 


\section{Contexto ambiental y geomorfológico}

El sitio arqueológico ILS1 se encuentra dentro de la Eco-región Delta e Islas del Paraná (Burkart et al. 1999), que se distribuye en forma concomitante con el río Paraná a lo lago de casi $900 \mathrm{~km}$. Este se comporta como un vector de humedad y temperatura, replicando en su desembocadura las condiciones ecológicas de los sectores más septentrionales de la cuenca. Ello ha permitido que este curso fluvial constituya un corredor biológico para la fauna, la flora y para las poblaciones humanas desde por lo menos el final del Pleistoceno (Popolizio 2003; Loponte y Acosta 2008a), generando en el extremo meridional un humedal continental de características subtropicales cuya productividad primaria está vinculada con los pulsos del río Paraná (ver un resumen en Loponte 2008). La fauna muestra un gran número de aves y mamíferos adaptados al ambiente palustre, constituyendo una de las regiones con mayor cantidad de avifauna y el sistema fluvial con mayor riqueza íctica de agua dulce de Argentina (López et al. 2002). La ictiofauna incluye peces estenohalinos con patrones estivales de migración, que se desencadenan a partir de cambios en la temperatura del agua (Bonetto et al. 1981; Oldani 1990; Amestoy y Fabiano 1992).

La región donde se encuentra el sitio ha cambiado profundamente a lo largo del Holoceno. Durante el límite Pleistoceno-Holoceno y Holoceno temprano, el nivel marino se encontraba por debajo de los $15 \mathrm{~m}$ (s.n.m). El río Paraná desembocaba al oriente de la costa uruguaya, en las inmediaciones de la ciudad de Punta del Este (Cavallotto et al. 2004, ver figura 2). En la

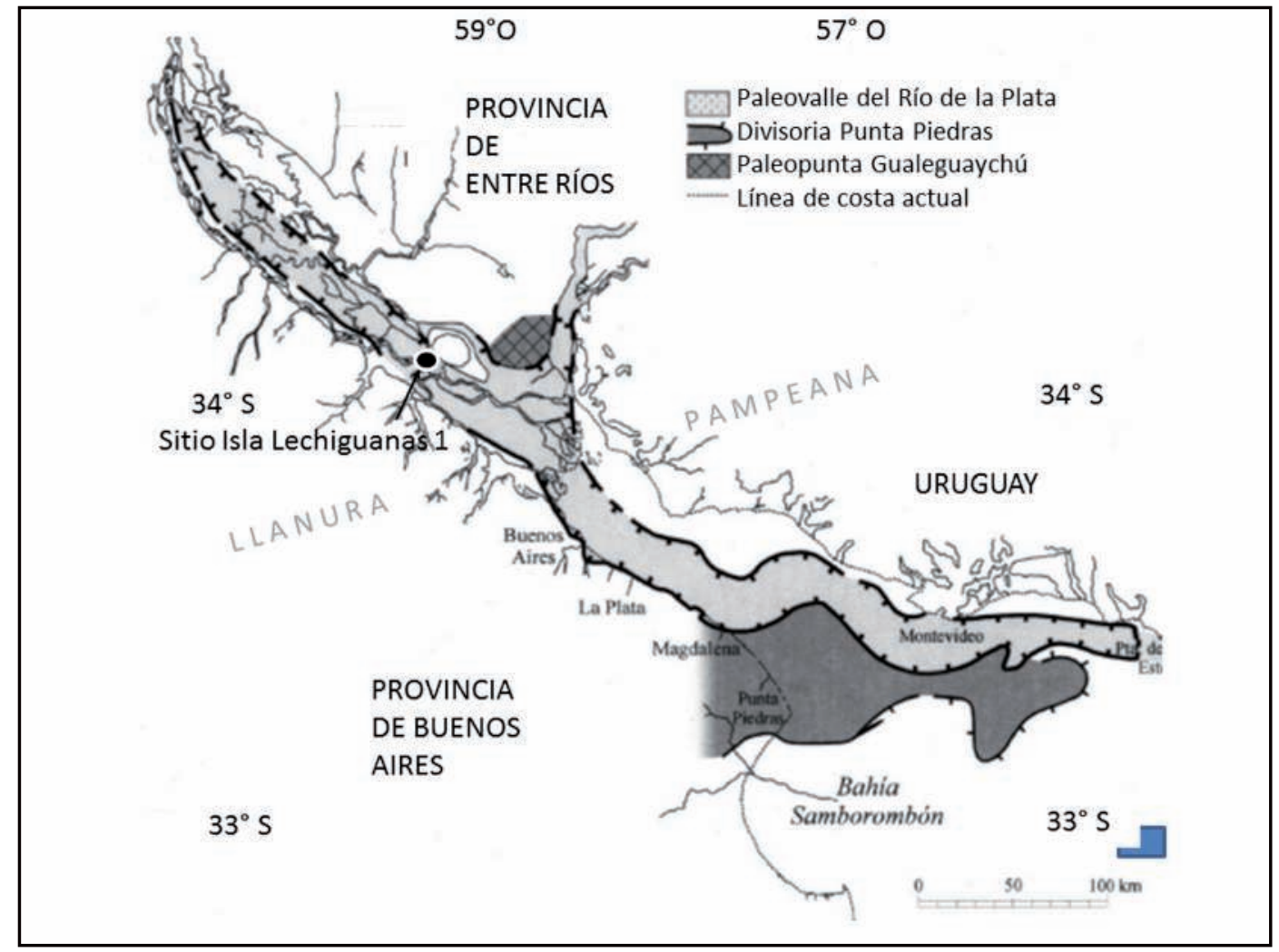

Figura 2.Canal del Pleistoceno-Holoceno temprano del río Paraná - Plata (tomado y modificado de Cavallotto et al. 2002). El sitio Isla Lechiguanas 1 está adyacente a la isla Ibicuy. 
zona que actualmente ocupa el Delta medio, donde se encuentra el sitio ILS1, se desarrollaba una llanura intersectada por el río Paraná. El ambiente estaba constituido por una estepa de gramíneas húmedas subhúmedas (Prieto et al. 2004; Tonello y Prieto 2010), interrumpida por una cuña con mayor cobertura arbórea que se desprendía desde el norte, parcialmente inducida por los colectores fluviales (Adams y Faure 1997), y que probablemente haya sido rápidamente jerarquizada por los humanos. Estas condiciones habrían generado espacios con baja resistividad a la circulación de las poblaciones humanas (cf. Kelly y Todd 1988). La significativa disminución en el caudal de los grandes ríos mesopotámicos debido a

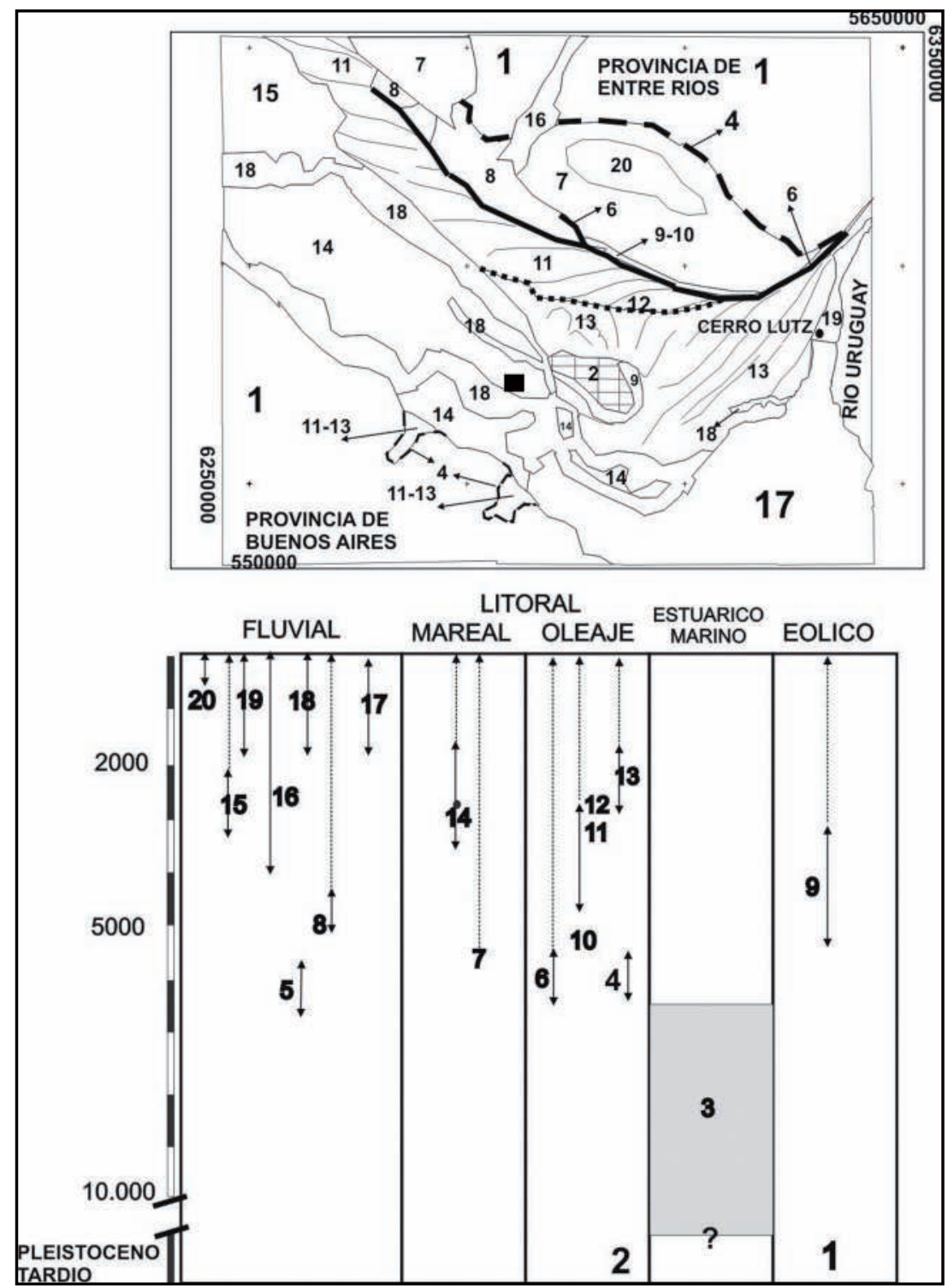

Figura 3. Las flechas indican desde qué momento cada una de los espacios quedaron disponibles para la ocupación humana durante el Holoceno. Las fechas anteriores a 3000 años AP deben considerarse con un error de \pm 500 años. El sitio ILS1, señalado con un punto, está ubicado en la saliente meridional de la unidad 14. 
precipitaciones inferiores a las actuales en sus cabeceras (entre 25\% y 35\% menos) (Cook y Vizy 2006), como así también por el descenso del nivel marino, facilitaron los movimientos entre las márgenes de los colectores, que se encontraban reducidos debido a los bajos niveles hídricos (Cavallotto et al. 2002).

Este panorama comenzó a modificarse hace 8000 años $\mathrm{C}^{14} \mathrm{AP}$ con el aumento del nivel de las aguas, que alcanzó la cota de -10 m (s.n.m), incrementando progresivamente el ancho de los cauces y ampliando en consecuencia la distancia entre ambas márgenes. Durante el Holoceno medio, esta tendencia continuó hasta que la altura del nivel marino se ubicó en un nivel similar al actual en 7000 años $C^{14}$ AP. Entre 6500 y 6000 años $C^{14}$ AP se registra el máximo transgresivo (+ 6,5 m.s.n.m), que generó un profundo golfo estuárico, fragmentando el paisaje y probablemente incentivando conductas divergentes entre poblaciones que durante del Holoceno temprano podrían haber tenido contactos frecuentes. El cortejo sedimentario de este período está integrado por la Formación Atalaya, que corresponde a una facies de estuario abierto, compuesto por arcillas limosas de color verdes con lentes intercalados de arenas muy finas y conchillas diseminadas o concentradas, y cuyo contenido fosilífero indica características estuáricas de aguas cálidas (Cavallotto 1996; Cavallotto et al. 2004, 2005; Fucks et al. 2005). En este contexto, la isla de Ibicuy, de aproximadamente unos $110 \mathrm{~km}^{2}$ y que está adyacente al sitio ILS1, quedó aislada a unos $20 \mathrm{~km}$ del sector continental más cercano. Aquí es factible considerar un proceso de abandono de la isla y/o su explotación ocasional, como también ocupaciones insulares más o menos permanentes durante el Holoceno medio. Con posterioridad al máximo transgresivo comienza una fase regresiva y la consecuente retracción hacia el sur del máximo gradiente salino. El nivel marino disminuyó en forma acentuada hasta 5000 años $\mathrm{C}^{14} \mathrm{AP}$, estabilizándose en $+5 \mathrm{~m}$ (s.n.m), el cual se habría mantenido hasta 3500 años $\mathrm{C}^{14}$ AP. A partir de esta fecha, el nivel de las aguas habría caído en forma relativamente brusca a $+2,5 \mathrm{~m}$ (s.n.m), disminuyendo progresivamente hasta llegar al nivel actual (Cavallotto et al. 2004). Según esta curva, el área donde se encuentra el sitio ILS1 debió haber quedado disponible para su ocupación a partir de 3500 años $\mathrm{C}^{14} \mathrm{AP}$ (ver figura 3).

\section{El contexto arqueológico}

Los cambios en el nivel marino, sorpresivamente, no fueron considerados en ninguna de las síntesis de la arqueología del litoral ni las recurrentes de la región Pampeana que incluyen a este sector (Berón y Politis 1997; Politis y Madrid 2001; Politis 2008). Estas oscilaciones han modificado sucesivamente el ambiente y la oferta de recursos asociada en el área, que fácilmente pueden integrarse dentro de un mínimo esquema predictivo que sirve para contextualizar el registro arqueológico conocido de la región (ver figura 4).

No conocemos con exactitud la cronología de las variaciones isohalinas a lo largo del estuario durante el Holoceno medio, para las cuales si bien hay referencias e información relacionada (Sprechmann 1978; Aguirre 1993; Fucks et al. 2005 entre otros), aún se requieren estudios de campo para determinarlas empíricamente. Esta falta de información impide demarcar con escalas temporales más precisas los previsibles cambios que tuvieron las economías aborígenes relacionadas con la migración del límite del máximo gradiente salino a lo largo del Holoceno ${ }^{2}$. En este sentido, el conocimiento de la arqueología del Holoceno medio está más desarrollado en la costa oriental del Río de la Plata. La información disponible allí, señala un importante aprovechamiento de fauna mixohalina en conjuntos datados a partir de 4800 años $\mathrm{C}^{14} \mathrm{AP}$ (Beovide 2011). Si bien los contextos arqueológicos están ubicados en 
el estuario intermedio y por lo tanto, las variaciones en la salinidad durante el Holoceno fueron y son diferentes, los conjuntos muestran una importante vinculación con una fauna esperable, o al menos con una parte de ella, para contextos arqueológicos del Paraná inferior durante el Holoceno medio.

Para este último sector, disponemos de una importante cantidad de información arqueológica para sitios bastante más tardíos, todos fechados con posterioridad a 1700 años $\mathrm{C}^{14} \mathrm{AP}$. Dichos conjuntos están insertos en una etapa netamente fluvial como la actual (ver figura 4). Excluyendo las colecciones faunísticas generadas por los horticultores amazónicos que penetraron en el área hace unos 800 años $\mathrm{AP}$, se conocen 11 contextos de cazadoresrecolectores que han sido fechados, estudiados y publicados con cierto grado de detalle, ubicados en la margen derecha de los ríos Paraná y Uruguay inferior (Acosta 2005; Loponte 2008, Acosta et al. 2010b, 2011a; Arrizurieta et al. 2010a). No incluiremos en este análisis algunos sitios que si bien cuentan con fechados, la calidad de la información disponible no es equivalente ${ }^{3}$. Los registros referidos muestran un aumento sostenido de la importancia de los peces en el tiempo, incremento que es concurrente con otras evidencias de intensificación (Loponte 2008; Acosta et al. 2010b). Entre ellas, la incorporación masiva de la alfarería como un equipo básico de la subsistencia, un aumento en el tamaño de las vasijas que incrementó la capacidad de procesamiento, la mayor fragmentación de los sistemas esqueléticos de las presas incluyendo los cráneos de los peces con el fin de maximizar los retornos, la captura de ejemplares con estadios madurativos más tempranos, tanto en los

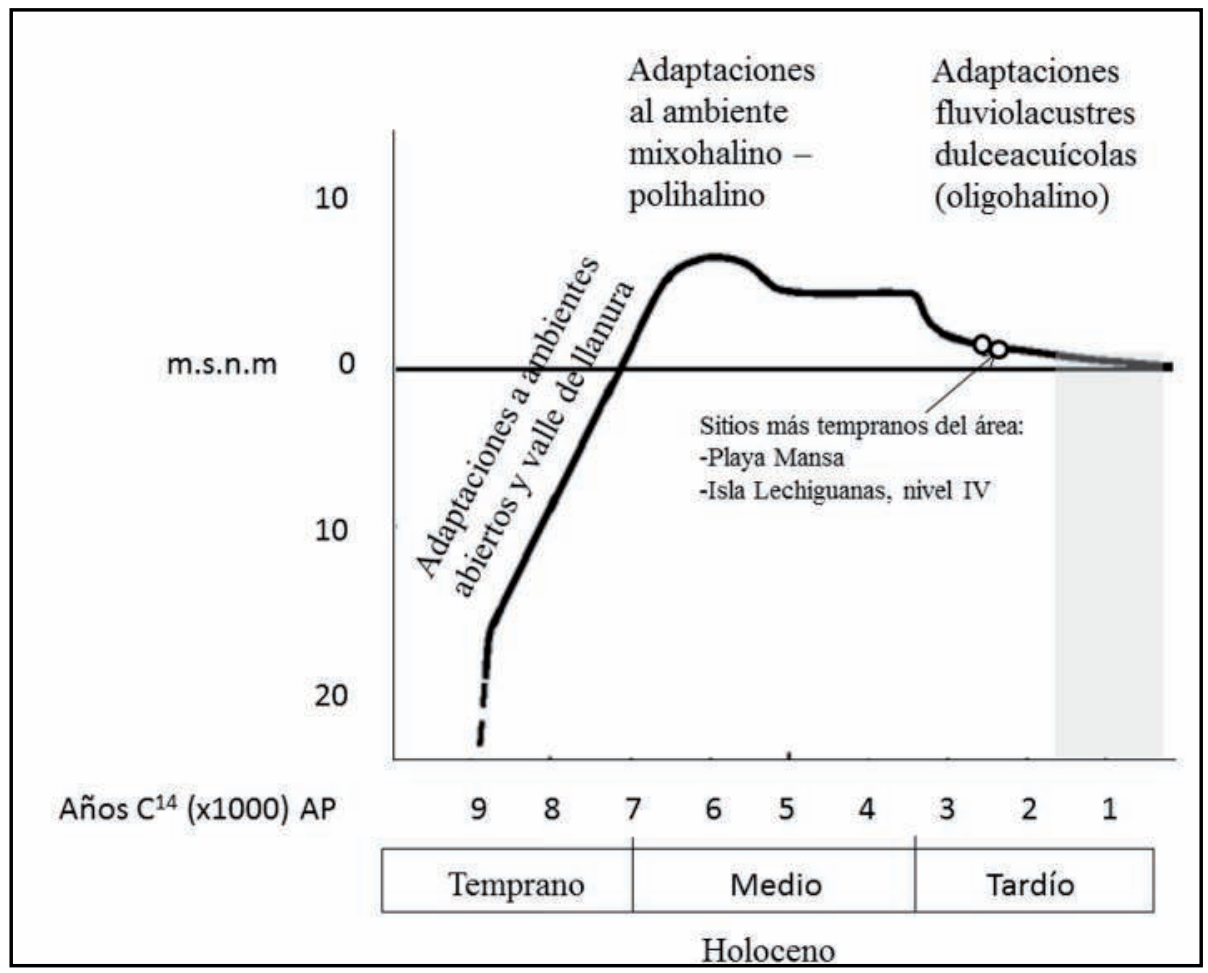

Figura 4. Cambios en el nivel marino y variaciones previstas en las adaptaciones humanas en el tramo final del Paraná-Uruguay inferior (el esquema está tomado y modificado de Loponte 2008). El sector en gris señala el período donde se concentra el registro arqueológico mejor conocido de la región. 
peces como en los mamíferos, y un alto componente de alimentos de origen vegetal. Esta última propiedad puede vincularse con la generación de paisajes antropizados a través de la manipulación de vegetales (i.e. "Paraná de las Palmas") y el desarrollo de prácticas agrícolas de pequeña escala. Esto habría implicado además, un aumento en la cooperación sexo-etaria en la obtención de los alimentos y la incorporación de recursos de muy bajo ranking como los moluscos fluviales, concomitante con el desarrollo de un sofisticado equipo de captura de presas. Este esquema se implementó a través de un sistema de asentamiento central (cf. Bettinger et al. 1997; Cannon 2003; Orians y Pearson 1979), lo cual implica alta estabilidad residencial. En este sentido, los estudios de remontaje y los análisis estilísticos de la alfarería, entre una serie más amplia de aspectos analizados, han demostrado que los sitios de los Bajíos Ribereños (margen continental derecha del río Paraná; ver figura 1) se generaron como producto de ocupaciones más o menos prolongadas, que generaron los mayores eventos de descarte de cada depósito. Si bien aún no existe un vector cronológico claro para otras conductas, es posible considerar un incremento en el nivel de interacción regional formalizado a través de alianzas con grupos locales y no locales mediante los cuales se adquirían regularmente bienes suntuarios extra-regionales, como los pendientes de malaquita, los metales y tal vez los cánidos domésticos. Por otro lado, la movilidad fluvial permitió no solo el desarrollo de rangos de explotación extendidos, sino también el intercambio basado en el transporte de volúmenes de productos (i.e. alimentos cultivados, farináceos, pesca, etc.), a diferencia del transporte del objeto que es la base del intercambio de los grupos pedestres. También se generaron en algún momento anterior a 1300 años $C^{14}$ $\mathrm{AP}$, espacios mortuorios segmentadosde los lugares residenciales que se emplearon por siglos como áreas funerarias, comportamientos territoriales concurrentes y tal vez algún grado de desigualdad institucionalizada, de la que aún no existe un registro arqueológico claro (ver Mazza y Loponte 2012). Este modelo resumido en algunos aspectos en Loponte (2008), se ha generado gracias a diferentes evidencias concurrentes provistas por varias líneas de investigación, y que continua ampliándose gracias a la elaboración de datos de estudios faunísticos (Loponte y Acosta 2004; Acosta 2005; Acosta et al. 2007a, 2007b; Loponte 2008; Loponte y Acosta 2008b; Arrizurieta et al. 2010a y 2010b; Parisi y Liotta 2008; Acosta y Mucciolo 2009; Acosta et al. 2010a, 2010b; Musali 2010; Mucciolo 2007; Loponte y Buc 2011, Acosta et al. 2011b entre otros), de tecnología ósea, malacológica y estudios de conjuntos líticos, incluyendo estudios de microdesgaste(Acosta et al. 2011c; Buc 2007; Buc y Loponte 2007; Buc y Silvestre 2010; Buc et al. 2010; Acosta et al. 2010a; Buc 2010a, 2010b, 2010c, 2011; Pérez Jimeno y Buc 2010; Loponte et al. 2011), isotópicos (Acosta y Loponte 2004; Loponte 2008; Loponte y Acosta 2007, 2008b), de tecnología cerámica y de estilos decorativos (Pérez y Cañardo 2004; Loponte 2008; Pérez y Montenegro 2009), incluyendo análisis de ácidos grasos y microrestos vegetales (Zucol y Loponte 2008; Pérez et al. 2011), comportamientos mortuorios (Loponte 2008; Mazza 2010; Mazza y Loponte 2011, 2012) y de sistemas de armas (Loponte 2008; Musali y Buc 2009; Sacur Silvestre et al. 2009; Acosta et al. 2010a; Buc $2010 \mathrm{a}, 2010 \mathrm{~b}$ y 2010c) entre otros trabajos ${ }^{4}$. Asimismo, estos resultados comenzaron a ser comparados con datos provenientes de otros sectores más septentrionales del Paraná, el Paraná medio y el estuario superior del Río de la Plata (Loponte y Acosta 2008b; Acosta et al. 2010b; Buc y Pérez Jimeno 2010; Pérez Jimeno y Buc 2010; Ottalagano y Pérez 2012), donde se genera nueva información en forma sistemática (Ottalagano 2007; FeuilletTerzaghi 2008; Coll 2011; Sartori y Colasurdo 2011 entre otros). Estas comparaciones no incluyen al Delta Superior, donde por el momento hemos podido comparar algunos datos basados en isótopos estables (Loponte y Kozameh 2010) y análisis comparativos de tecnología cerámica mediante cortes delgados (Ottalagano y Pérez 2012). Las investigaciones que recientemente ha comenzado Ottalagano (com. pers. 2011) en el Delta Superior y en áreas adyacentes, se- 
guramente permitirán obtener nueva información al respecto en el corto y mediano plazo. Otros trabajos recientes en el área insular al norte del Paraná Pavón, como los efectuados por Bonomo et al. (2011) se han centrado en analizar materiales depositados en museos (ver también Lanzelotti et al. 2011), la mayoría de los cuales fueron recuperados a principios del siglo XIX o mediados del siglo pasado; también han contribuido en la importante tarea de generar mapas arqueológicos para un sector del Delta Superior y en la obtención de fechados radiocarbónicos de colecciones museológicas que en su mayoría son bastante tardías, y de algunos nuevos sitios de los cuales aún hay poca información publicada, pero que esperamos se incremente en el futuro.

Dentro de este contexto, la importancia del nivel acerámico del sitio ILS1, radica en que junto con Playa Mansa, son los dos sitios arqueológicos más antiguos conocidos de la región, y que se desagregan del paquete de información que disponemos con posterioridad a 1700 años $C^{14}$ AP. El sitio Playa Mansa, que se ubica en el borde oriental de la Pampa Ondulada, dentro del valle de inundación del río Paraná, fue excavado por Sandra Escudero en diversas campañas. Esta investigadora recuperó un contexto con cerámica fechado en $2400 \pm 20$ años $\mathrm{C}^{14}$ AP (2370 - 2473 años cal. AP; UGAMS-03302; Acosta et al. 2010b). La fauna asociada ya muestra una adaptación a los recursos fluvio-lacustres y una oferta similar a la actual (Acosta et al. 2010b; Sartori y Colasurdo 2011) ${ }^{5}$. Por el contrario, ILS1 se ubica en pleno Delta medio, en el sector insular del Paraná inferior, y su nivel IV es acerámico. Estas notables diferencias impactaron de una forma sustancial en las estrategias de subsistencia, lo cual nos permite avanzar en el conocimiento de la variabilidad arqueológica de la mitad del Holoceno tardío en la región, y explorar la secuencia evolutiva de una manera que hasta el momento no podíamos hacerlo. Esto resalta la importancia del trabajo de Caggiano (1977), quien reconoció y seleccionó este sitio debido a sus características excepcionales para el área. Luego de 35 años de estas investigaciones pioneras, obviamente, las preguntas se han diversificado y profundizado, lo que requiere la generación de nuevas clases de datos. Además, disponer de un conjunto sin cerámica, es una formidable oportunidad para contrastar algunos aspectos dentro un modelo que generó expectativas predictivas sobre algunas de las propiedades que se esperan encontrar en conjuntos más tempranos del Holoceno tardío.

\section{El sitio arqueológico Isla Lechiguanas 1}

El sitio ILS1 se encuentra en el Delta medio, en el sur de la isla Lechiguanas, en un albardón de $750 \mathrm{~m}^{2}$ aproximadamente a $300 \mathrm{~m}$ de la margen izquierda del río Paraná de las Palmas (ver figura 5). El área dondé se encuentra el sitio tiene una elevación que oscila entre 2 y 2,5 m (s.n.m). La altura máxima del albardón en relación a su nivel de base es aproximadamente $1,5 \mathrm{~m}$.

En el año 2011 se excavaron $8 \mathrm{~m}^{2}$ en el sector noroeste del mismo, a través de las cuadrículas 1 y 2, cada una de $4 \mathrm{~m}^{2}$. El nivel estéril se alcanzó entre los 80 y $100 \mathrm{~cm}$ de profundidad, lo que representa aproximadamente $7 \mathrm{~m}^{3}$ de sedimento removido.

Caggiano (1977; ver también Cione y Tonni 1978), quien habría removido alrededor de $18 \mathrm{~m}^{2}$, determinó la existencia de seis niveles que numeró consecutivamente de arriba hacia abajo y que son consistentes con los perfiles expuestos en la temporada 2011. Siguiendo la estratigrafía elaborada por Caggiano, el nivel I corresponde a la champa $(\leq 7 \mathrm{~cm})$, que contiene materiales faunísticos exóticos; el nivel II está compuesto por el horizonte de suelo actual, con abundante cantidad de restos de fauna autóctona, instrumentos óseos y 


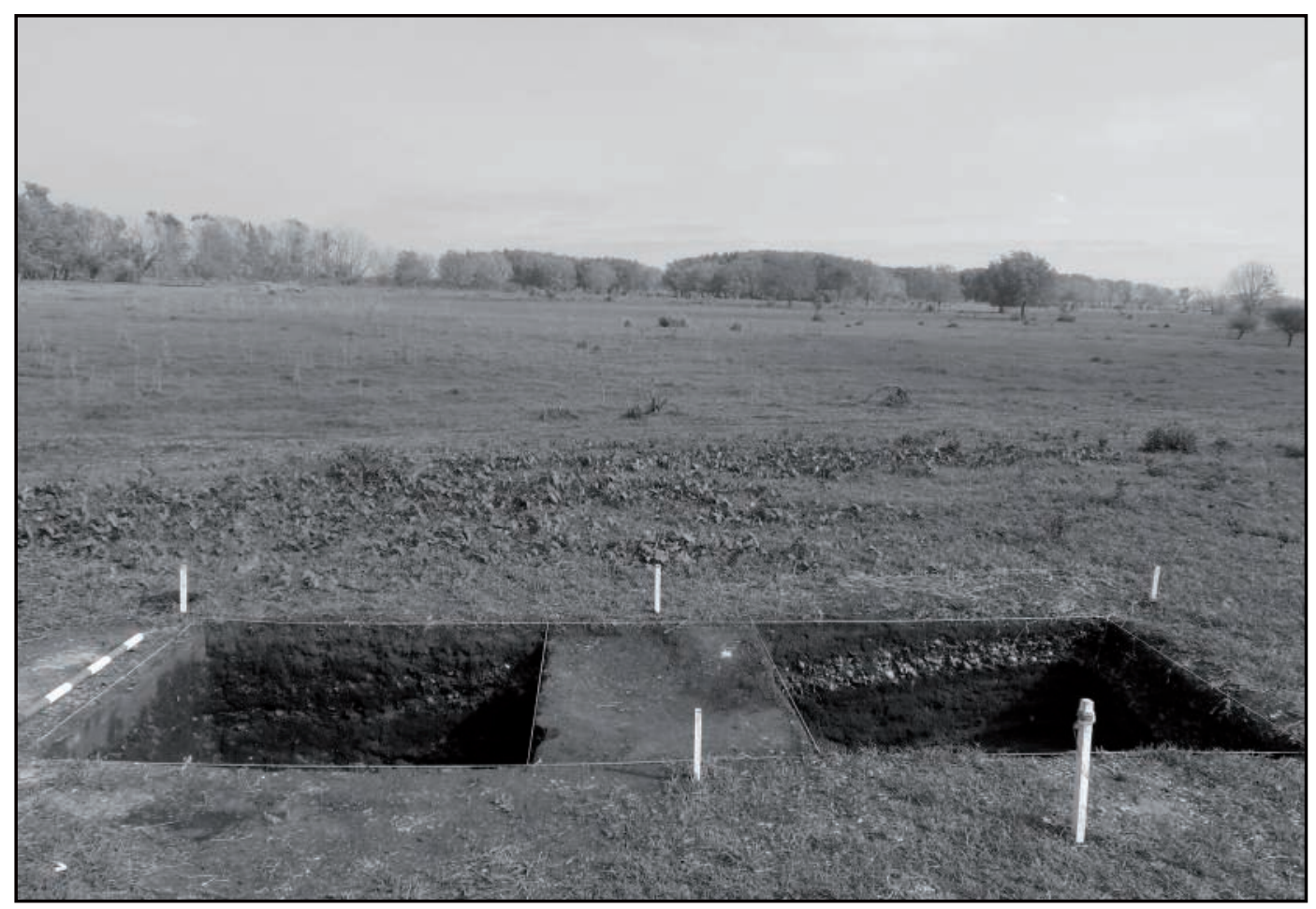

Figura 5. Vista del sector noroeste del sitio ILS1. En primer plano, las cuadrículas 1 y 2 excavadas en la temporada de 2011.

cerámica lisa e incisa con una densidad promedio ${ }^{6}$ para este nivel de 490 fragmentos $/ \mathrm{m}^{3}$. La potencia del mismo oscila entre 15 y $35 \mathrm{~cm}$. Un fechado radiocarbónico de este contexto arrojó una antigüedad de $408 \pm 30$ años $\mathrm{C}^{14} \mathrm{AP}$ (AA97462). La muestra fechada corresponde a un fragmento óseo de Myocastor coypus $\left(\delta \mathrm{C}^{13}-21,2 \%\right.$ ).

Debajo del nivel cerámico se encuentra el nivel III, integrado por un conchero de valvas de Ampullaria sp., que presentan individuos sin selectividad dimensional aparente. La fracción predominante está constituida por valvas íntegras, y en menor proporción se reconocen ejemplares con diferente grado de fragmentación, incluyendo algunas completamente colapsadas in situ. El conchero no tiene una superficie uniforme, sino que presenta ondulaciones en su techo y base y oscilaciones de su potencia a lo largo de los perfiles expuestos. El espesor promedio es de alrededor de $30 \mathrm{~cm}$, con potencias mínimas de $16 \mathrm{~cm}$ y máximas de $55 \mathrm{~cm}$. La compactación de las valvas hace que su remoción constituya una tarea compleja y ardua. En algunos puntos del conchero, se observan pequeños lentes de arena amarilla de $2 \mathrm{a} 4 \mathrm{~cm}$ de espesor, que ocasionalmente pueden contener algunos ejemplares de Diplodon sp., Endodontidae sp. y escasos restos faunísticos de vertebrados (ver también Cione y Tonni 1978). Las valvas de Diplodon sp. se presentan en posición de vida, es decir articuladas y descansan en posición horizontal, mientras que los escasos restos óseos no presentan evidencias de interacción humana. No se recuperaron artefactos en este nivel. Caggiano (1977) y Cione y Tonni (1978) consideraron que su formación es de origen natural, hipótesis que por el momento parece la más probable. Debido a la tenacidad, compactación y distribución del mismo, este conchal ha actuado como un sello estratigráfico entre el nivel II (cerámico) y el nivel IV (acerámico). Dos fechados radiocarbónicos efectuados sobre estas valvas arrojaron 
edades de $2740 \pm 80$ y $2550 \pm 90$ años $C^{14}$ (INGEIS: AC-0122 y AC-0124, también referidos como "INGEIS 1999" e "INGEIS 2000"; ver Caggiano 1984). No existe información respecto a si estos fechados fueron obtenidos con valvas procedentes de diferentes profundidades del nivel III. La superposición de los fechados calibrados ${ }^{7}(3000$ - 2502 y 2750 - 2335 años cal. AP; $95,4 \%$ de probabilidad) y la ausencia de hiatos de relevancia observados en este nivel, sugieren que esta unidad es el producto de uno o de varios episodios de acumulación por anegamiento escasamente separados en el tiempo.

Por debajo del conchero del nivel III, se encuentra un paleosuelo sin estratificación visible ${ }^{8}$ que define el nivel IV desarrollado a expensas de arenas gruesas, cuya potencia oscila entre 8 y $30 \mathrm{~cm}$ según Caggiano, pero que en el sector excavado en 2011 alcanza hasta $50 \mathrm{~cm}$. Este nivel posee abundante cantidad de restos faunísticos desarticulados, astillas procedentes de huesos largos con puntos de percusión y fracturas obtenidas en estado fresco, huesos con aserrado perimetral recto y oblicuo, diversos tipos de instrumentos óseos y desechos de manufactura de los mismos. Una fracción de las partículas arqueológicas presenta incrustaciones carbonáticas, que también están incorporados en el sedimento. Tanto en las excavaciones de Caggiano, como en las nuestras, no se detectó un solo fragmento de cerámica'. Tampoco se identificaron concentraciones de valvas de moluscos fluviales, más allá

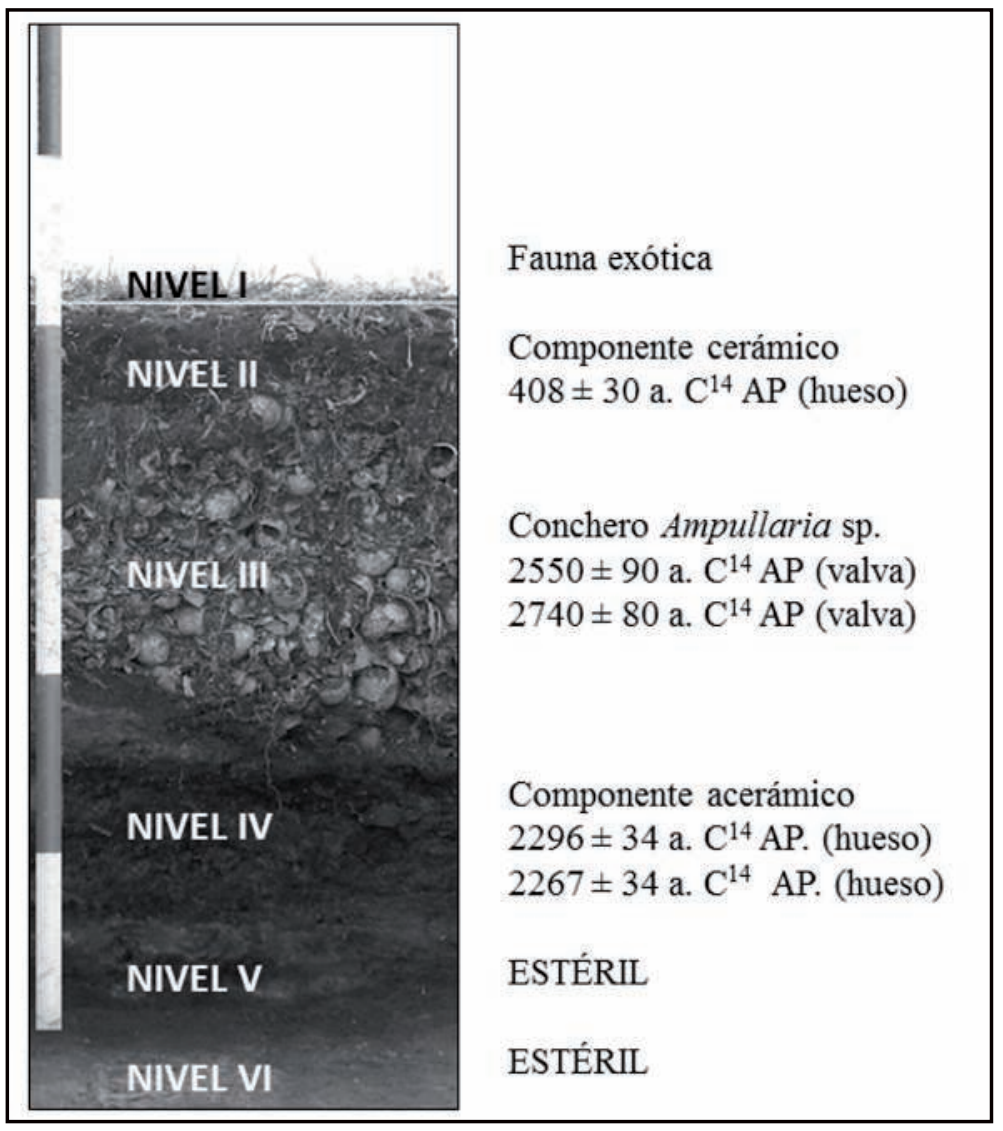

Figura 6. Sitio Isla Lechiguanas 1. Perfil Norte de la cuadrícula 1. La escala posee segmentos de $20 \mathrm{~cm}$. 
de algunos ejemplares aislados y desarticulados de Diplodon sp. Se fecharon dos muestras procedentes de diferentes unidades artificiales de extracción de este nivel, constituidas por falanges de Blastocerus dichotomus (ciervo de los pantanos), una de las cuales presentaba fractura en estado fresco. La primera, que corresponde a un individuo juvenil, fue recuperada del intervalo 70-80 (techo del nivel IV), y la segunda, que pertenece a un ejemplar adulto, proviene del intervalo de extracción $90-100 \mathrm{~cm}$ (base del nivel IV). Las edades obtenidas son $2296 \pm 34$ años $C^{14}$ AP (AA97467; $\delta C^{13}-21,4 \%$; $2342-2153$ años cal. AP) y $2267 \pm 34$ años $C^{14}$ AP (AA97461; $\delta C^{13}-21,2 \%$; 2336 - 2135 años cal. AP). Ambos fechados calibrados en años calendáricos con un $95,4 \%$ de probabilidad, se superponen armoniosamente, lo que sugiere que el nivel IV se generó como producto de una ocupación, o de varias separadas por un corto período de tiempo arqueológico.

Por debajo de este paleosuelo, se desarrollan los niveles V y VI, que están compuestos básicamente por arenas con diferente grado de selección, textura y color y que son arqueológicamente estériles. Poseen concreciones ferruginosas, con escasos restos faunísticos y moluscos fluviales en posición de vida. Constituyen antiguas facies de canales o de lagunas fluviales. En la figura 6 se observa uno de los perfiles del sitio.

\section{Resultados}

\section{Edades radiocarbónicas}

Como señalamos, Caggiano obtuvo dos fechados radiocarbónicos sobre las valvas del conchero que forman el nivel III. Bonomo y colaboradores sugirieron tomar con "cautela" estos fechados ya que "no estaban directamente asociadas con una ocupación humana" (Bonomo et al. 2011: 314). Esta "cautela" fue repetida por Lanzelotti et al.(2011). Sin embargo, Caggiano nunca consideró que había fechado las ocupaciones en forma directa, sino en términos relativos, como así también fue interpretado por Gasparini y Soibelzon (2011). Esta investigadora, además, señaló las características ya citadas más arriba respecto a la integridad y compactación de este conchero, por lo que no existían evidencias disponibles de estratigrafía invertida o mezclas de materiales. Desde el siglo XVII es una práctica establecida por la geología (Hamblin 1978), y también por la arqueología como mínimo hace casi 100 años (Droop 1915), reconocer que los niveles inferiores son más antiguos que los niveles suprayacentes, y a la inversa, los que están por encima son más modernos (véase también Harris 1989). Las excavaciones efectuadas en la temporada 2011 tampoco han permitido identificar situaciones de estratigrafía invertida, confirmando las observaciones de Caggiano respecto a la alta integridad de este conchero y su compactación masiva. Por lo tanto, esos fechados deben ser interpretados como edades máximas para el nivel II, y mínimas para el nivel IV. Sin embargo, dado que los materiales datados son exoesqueletos de origen fluvial, estas edades relativas estaban influenciadas en algún grado por el efecto reservorio, cuya magnitud era desconocida.

Las diferencias en el contenido de $\mathrm{C}^{14}$ entre los sistemas terrestres y fluviales fueron teorizadas por Godwin (1951), quien sugirió que los carbonatos disueltos de las calizas podrían introducir errores azarosos en los fechados de los carbonatos precipitados de los ambientes fluviales, lo cual fue corroborado por diversos autores, entre ellos Blau et al. (1953), Deevey Jr. et al. (1954), Broecker y Walton (1959), Rubin y Taylor (1963), Broecker (1964) y Geyh et al. (1998). También se sugirió que la descomposición de viejos niveles húmicos constituirían una fuente de $\mathrm{C}^{14}$ antiguo que fácilmente podría circular por los ambientes fluviales e incorporarse en los organismos vivos (Keith y Eichler 1963), aunque algunos autores basados 
en diferentes tipos de evidencias, han desestimado esta idea (Broecker 1964). Los análisis comparados entre dataciones de distintos tipos de materiales y también los cruzamientos con edades radiocarbónicas marinas calibradas, determinaron que el efecto reservorio está mediado por la especie, el ambiente y el período analizado, debido a ciclos geo-ecológicos diferentes y estilos de vida distintos (Tamers 1970; Berger y Meek 1992). Por ejemplo, en el caso de Anodonta sp., en la cuenca del río Mojave, se determinó en -450 años $C^{14}$ el efecto reservorio de sus valvas, mientras que en la región de los lagos Buena Vista en California, Sutton y Orfila (2003) estimaron un efecto reservorio de -300 años $C^{14}$. Valores similares (-340 \pm 20 años $\mathrm{C}^{14}$ ) para el mismo género y área fueron alcanzados por Culleton (2006). Existen análisis efectuados en otras especies de agua dulce para otras regiones del mundo, donde se demostró la existencia de un importante efecto reservorio de los carbonatos de los moluscos dulceacuícolas (Burleigh y Kerney, 1982; Goodfriend y Hood 1983; Figini et al. 1989; Jackson

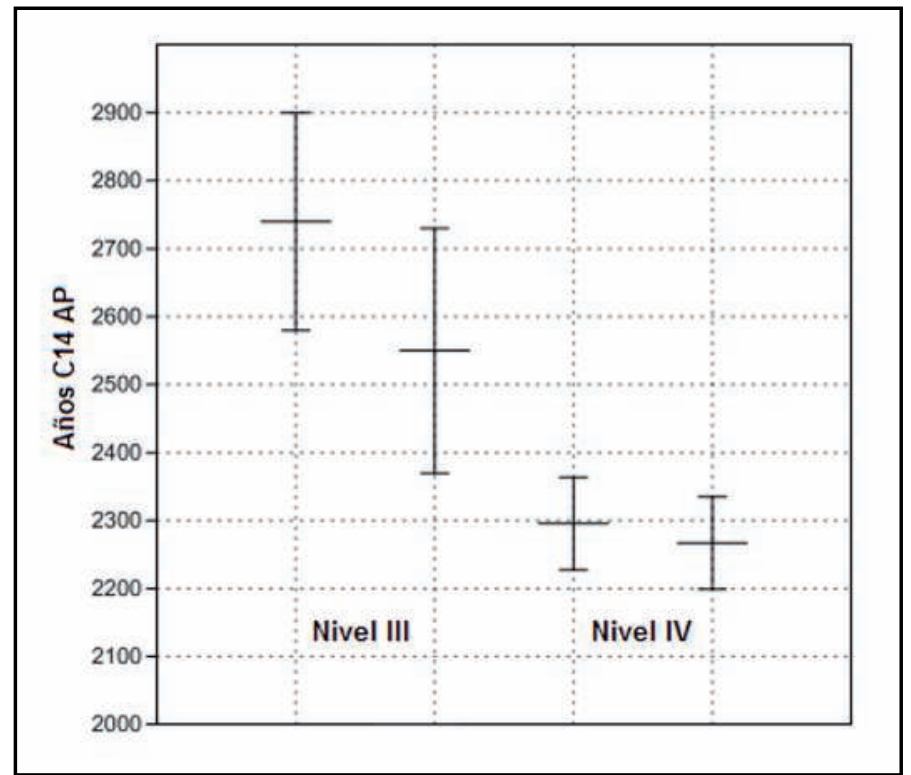

Figura 7. Edades en años $C^{14} A P( \pm 2 \sigma)$ de los niveles III y IV del sitio ILS1.

et al. 1999; Tonni et al. 2001; Gillespie et al. 2009), como así también en los residuos adheridos a las vasijas, producto del hervido de los moluscos fluviales y de los peces, con valores de efecto reservorio que oscilan entre -199 y -500 años $C^{14}$ (Fischer y Heinemeier 2003). Dado estos resultados, existe una amplia coincidencia entre diferentes autores en evitar la utilización de fechados radiocarbónicos sobre valvas, sean estas marinas o fluviales, siendo en general utilizadas cuando no hay otros materiales fechables disponibles.

En el sitio ILS1, la mayor antigüedad del nivel III respecto a al nivel IV, el cual es inmediatamente inferior, demuestra claramente la existencia de un efecto reservorio en las valvas de Ampullaria sp. La magnitud del mismo es de -364 años $\mathrm{C}^{14}$ y -406 años calendáricos en términos promediados. Estos valores deben considerarse mínimos hasta tanto no se obtengan fechados sobre colágeno o carbón provenientes del mismo conchero (ver figura 7). Asimismo, estos resultados nos advierten sobre la representatividad y relativa precisión de los fechados realizados sobre carbonatos de origen fluvial, algunos de ellos obtenidos recientemente en la arqueología local para sitios del área (i.e. Albero y Angiolini 1985; Politis et al. 2010; Bonomo et al. 2011). 
Colección faunística

La colección faunística recuperada en las cuadrículas 1 y 2 asciende a 5114 restos $^{10}$. Los restos óseos presentan una coloración oscura y mayor densidad mineral que sus homólogos actuales, producto de un proceso de depositación y remplazo del tejido óseo por parte de sales, óxidos y/o hidróxidos de estroncio, hierro y manganeso, (cf. Badone y Farquhar 1982; Houston et al. 1966; Stephan 1997; Toots 1963). Este proceso diagenético, que ha sido detectado en los sitios de la margen derecha del río Paraná y en otro sectores de la cuenca (Acosta 2005; Loponte 2008; Pérez Jimeno 2007; Sartori y Colasurdo 2011; Santini y De Santis 2011), produce graduaciones del color que varían del marrón al negro. Otros efectos son el aspecto metaloide de los huesos y el aumento de la densidad mineral ósea, debido al alto peso específico de estos metales, fundamentalmente del hierro. Este proceso que está documentado localmente en diversos depósitos donde se desarrollan Molisoles, aumenta la capacidad de supervivencia de los conjuntos óseos ( $c f$. Acosta 2005; Loponte 2008; Musali 2010). En este depósito se suma además un proceso de carbonatización de las superficies óseas, que ha mantenido algunas estructuras anatómicas unidas, las cuales probablemente fueron descartadas cuando tenían tejido conectivo. Esto se ha verificado en algunos carpos y tarsos de Myocastor coypus y en metapodios de cérvidos que conservan sus respectivos huesos carpianos/tarsianos. La buena integridad del conjunto también se manifiesta por un bajo estadio de meteorización que se ubica entre 1 y 2 ( $c f$. Behrensmeyer 1978) y la casi nula incidencia de carnívoros y roedores, lo cual también sucede en todos los conjuntos conocidos del Holoceno en el área (Acosta 2005; Loponte 2008; Acosta y Mucciolo 2009; Arrizurieta et al. 2010a; Musali 2010; Sartori y Colasurdo 2011).

\begin{tabular}{|lcc|}
\hline \multicolumn{1}{c}{ TAXON } & NISP & \%NISP \\
\hline Actinopterygii & 3510 & 68,64 \\
Aves & 5 & 0,10 \\
Mammalia (1) & 25 & 0,49 \\
Mammalia (2) & 333 & 6,51 \\
B. dichotomus & 139 & 2,72 \\
O. bezoarticus & 4 & 0,08 \\
L. guanicoe & 3 & 0,06 \\
H. hydrochaeris & 21 & 0,41 \\
M. coypus & 1074 & 21,00 \\
\hline TOTAL & 5114 & 100,00 \\
\hline Diversidad (Simpson) & 0,4 & \\
Índice de Peces & 0,69 & \\
\hline
\end{tabular}

Tabla 1. Isla Lechiguana 1, nivel IV. Valores de NISP, excluyendo los artefactos formatizados. (1) corresponde a astillas de mamíferos de tamaño pequeño, menores a $10 \mathrm{~kg}$ de peso. (2) corresponden a mamíferos de tamaño mediano a grandes, mayores a $20 \mathrm{~kg}$ de peso. El indice de peces sigue las relaciones propuestas por Lyman (2003) ${ }^{11}$, y está calculado según 1- [ $\Sigma$ NISP mamíferos / ( $\Sigma$ NISP mamíferos $+\Sigma$ NISP peces)] (ver Loponte 2008). 
La composición del conjunto faunístico está dominada por restos de peces y mamíferos. Si bien por el momento aquí presentaremos los valores de NISP, ya que la colección está aún en proceso de análisis, estos datos nos permiten comparar valores de abundancia y diferentes índices de proporción relativa con otros conjuntos recuperados en la margen derecha de los ríos Paraná y Uruguay, próximos a ILS1 (ver figura 1 y tabla 1).

Entre los peces, los Siluriformes y especialmente Pterodoras granulosus (armado) son lo que poseen más visibilidad a ojo desnudo (Loponte 2008; Loponte et al. 2009). Esta especie se captura en el área entre mediados de la primavera y fin del verano ( $c f$. Bonetto et al. 1981; Oldani 1990; Amestoy y Fabiano 1992). También hay numerosos restos de los grandes ictiófagos del sistema fluvial del Paraná (Pseudoplatystoma sp.) (verfiguras 8 y 9). Aún no se han efectuado estudios radiológicos sobre las abundantes vértebras pequeñas que integran la colección, los cuales son indispensables para reconocer la incidencia de los Characiformes en los conjuntos del área (Loponte 2008; Loponte et al. 2009).

No se detectaron restos de Pogonias cromis (corvina negra), frecuente en los sitios del estuario intermedio y exterior (Brunazzo 1999; Paleo y Pérez Meroni 2004, 2007; Beovide 2011), ambos sectores tuvieron aguas mixohalinas durante el Holoceno tardío, característica que aún conservan en la actualidad, si bien probablemente con gradientes temporales decrecientes, particularmente en el estuario intermedio de la costa occidental del Río de la Plata.

A diferencia de todos los conjuntos de la fase final del Holoceno reciente, se detectaron escasos fragmentos de cráneos de $P$. granulosus. Esta región anatómica es muy abundante en los sitios que poseen cerámica en el área. Una observación similar fue efectuada por Cione y Tonni (1978) sobre el conjunto óseo recuperado por Caggiano, si bien estos autores no especifican si esta observación es válida para uno o los dos niveles culturales del sitio.

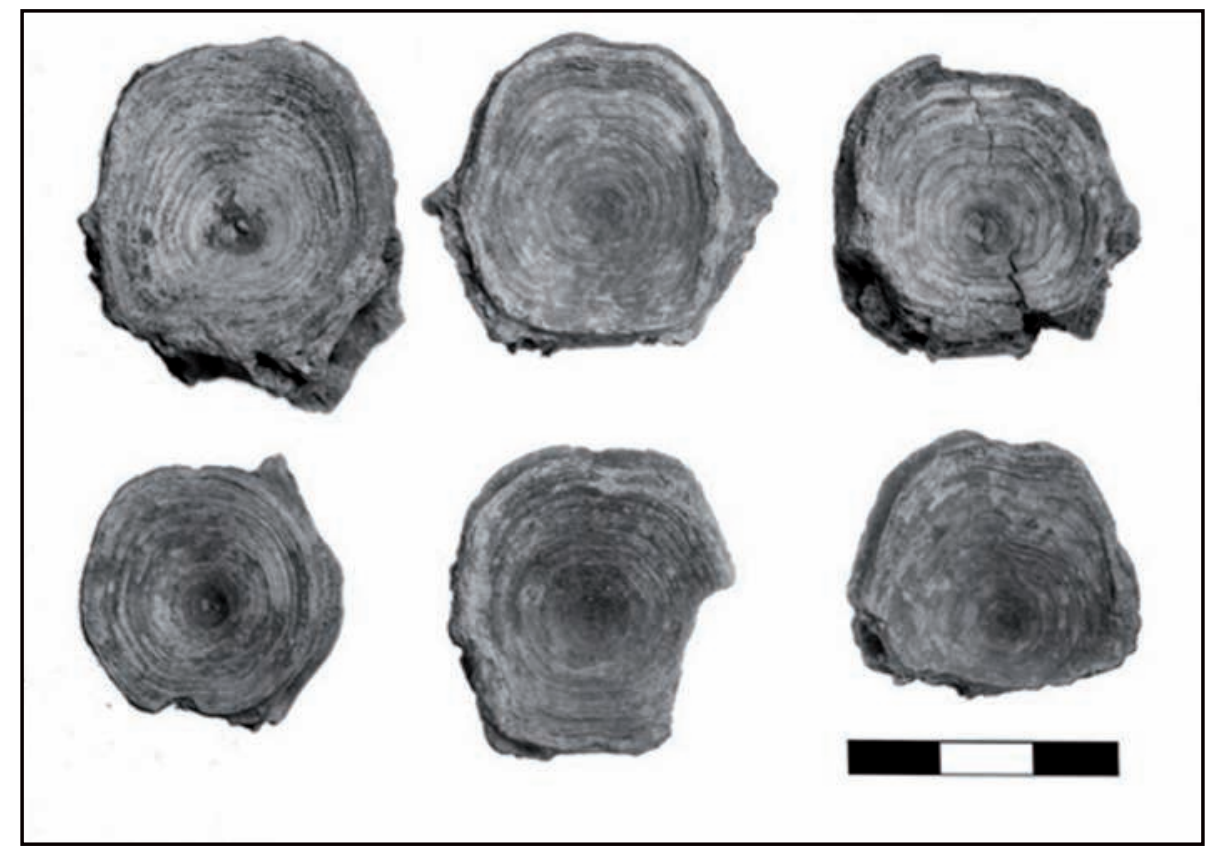

Figura 8. Isla Lechiguanas sitio 1, nivel IV. Vértebras de Siluriformes (cf.Pseudoplatystoma sp.) 


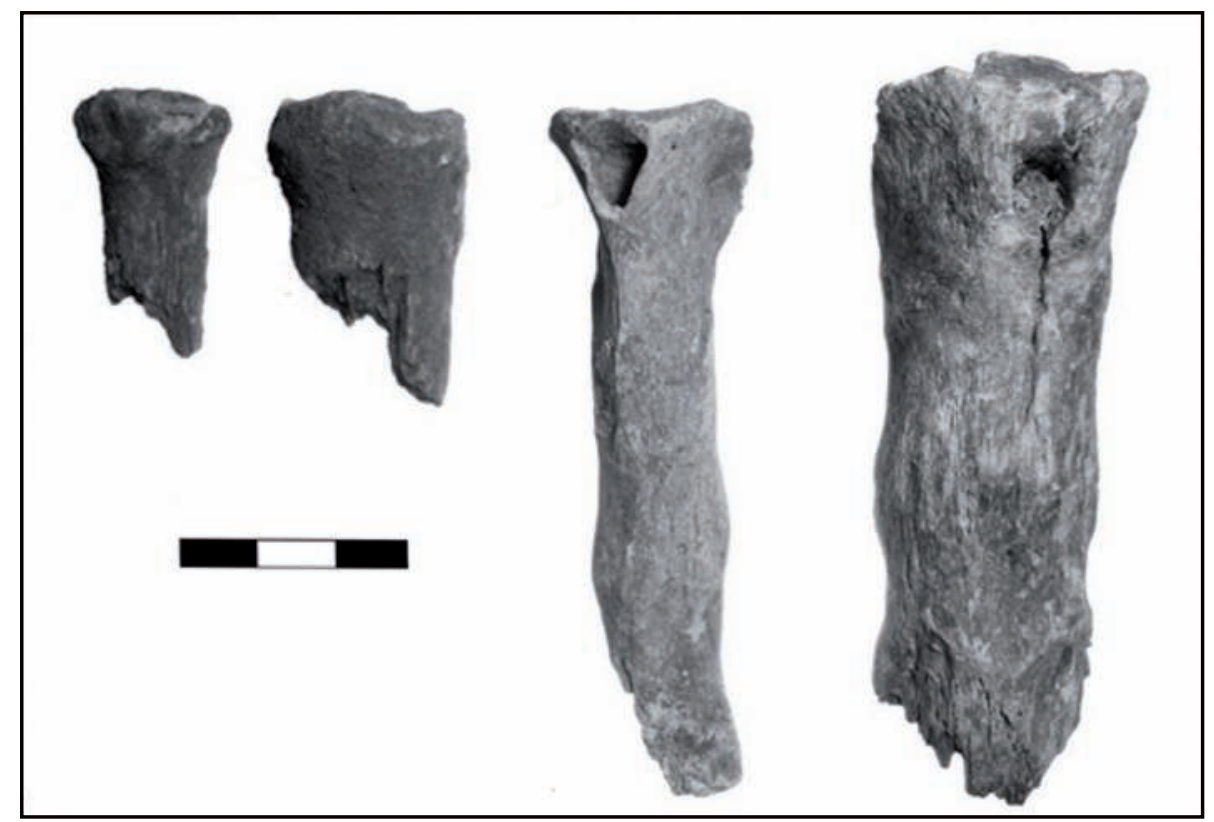

Figura 9. Sitio Isla Lechiguanas 1, nivel IV. Basioccipitales de Pseudoplatystoma sp.

La técnica de captura especialmente de los peces no demersales pudo ser implementada mediante el empleo de arpones con punta separable, muy comunes en este nivel. Estos poseen un mismo bauplan a lo largo del Holoceno tardío (Loponte 2008; Buc 2010a, 2010b; Buc y Pérez Jimeno 2010). En el nivel IV de este sitio muestran un estilo peculiar, con dientes proximales muy agudos, y la ventana de sujeción con una sección circular (ver figura 10; una discusión respecto puede verse en Buc 2010a, 2010b y Buc y Silvestre 2010).

En ILS1 no se detectaron pesos de red, ausencia que se verifica en todos los sitios más tardíos de la región. La presencia de peces de hábitos demersales, sugiere el uso de redes de pesca de manipulación directa, como las redes en forma de bolsa o de tijera, comunes en todo el noreste argentino desde el siglo XVI (cf. Loponte 2008; Musali 2010) hasta épocas contemporáneas (Scarpa 2007). El empleo de redes y arpones permite una mayor flexibilidad para la captura tanto en las canchas de pesca centrales y laterales, como así también en la llanura de inundación, donde se produce la dispersión de algunas especies de peces en forma concurrente con la crecida regular y estival del Paraná.

Entre los mamíferos se destaca la gran cantidad de restos óseos de M. coypus y de $B$. dichotomus, observación que también coincide con el análisis de Cione y Tonni (1978). Los elementos reconocidos de ambas especies incluyen las regiones axiales y apendiculares, señalando el ingreso completo de los ejemplares capturados. En el caso de B. dichotomus, además de diferentes huesos largos de los quiridios, se reconocieron vértebras cervicales, torácicas y lumbares, como así también probablemente costillas, que permanecen identificadas en la categoría de grandes mamíferos. De igual forma, es probable que una fracción de los fragmentos identificados como "mamíferos de más de $20 \mathrm{~kg}$ de peso" de la tabla 1 correspondan a este ungulado. Un análisis más detallado de estos especímenes está siendo efectuado por unos de los autores (LM). 


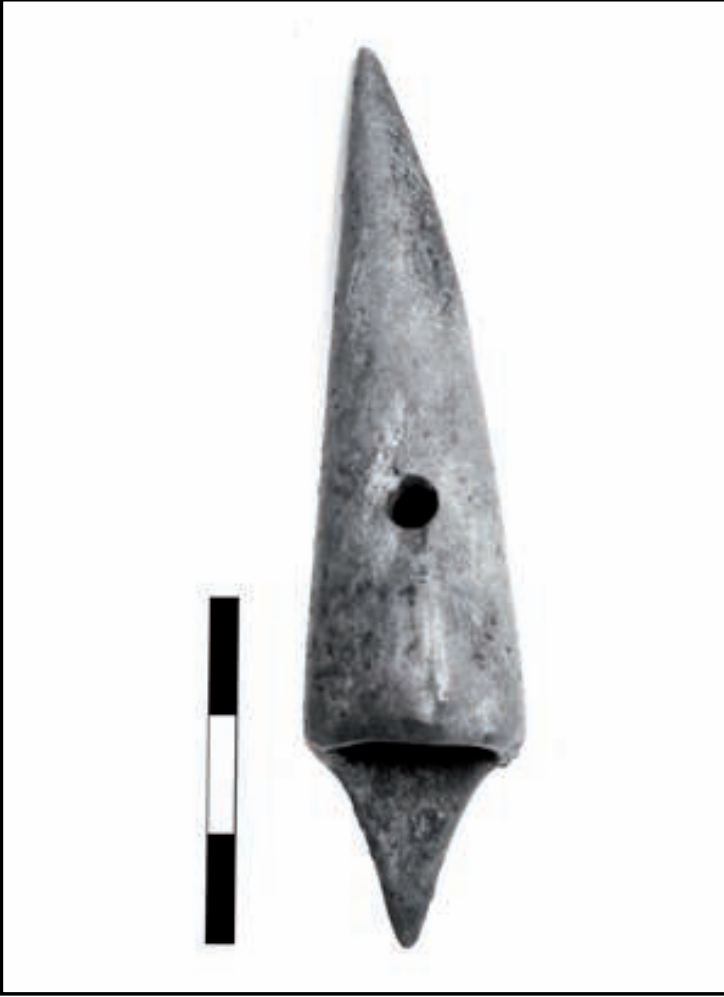

Figura 10. Sitio Isla Lechiguanas 1, nivel IV. Cabezal de arpón pedunculado.
Los escasos elementos óseos identificados de Hydrochaeris hydrochaeris (carpincho) corresponden a huesos del autopodio y del cráneo. Este patrón de representación es similar al que se registra en los sitios más tardíos del área (Acosta 2005; Loponte 2008; Arrizurieta et al. 2010a). Para el caso de los dos taxones de ambientes más abiertos, Ozotoceros bezoarticus (venado de las pampas) y Lama guanicoe (guanaco), sólo se detectaron elementos de los quiridios.

Las evidencias de interacción entre las especies identificadas y la conducta humana son múltiples. Se identificaron negativos de impacto y fracturas en estado fresco en huesos de $M$. coypus, $B$. dichotomus y L. guanicoe. Particularmente es significativa la importante fracción de huesos del segundo taxón con huellas de percusión. Algunos especímenes de espinas de $P$. granulosus también fueron fragmentadas en sectores adyacentes a su articulación, sugiriendo que esta fractura corresponde a una conducta destinada a disminuir el riesgo en su manipulación (Acosta 2005; Musali 2010). También se recuperaron instrumentos confeccionados con elementos óseos de $B$. dichotomus como así también desechos de manufactura en hueso y en astas de Cervidae ( $c f$. B. dichotomus).

Entre los restos vegetales, se identificaron endocarpos carbonizados de Syagrus Romanzzofiana (Pindó). Algunos están enteros, y otros corresponden a fragmentos muy pequeños. Esta es una especie frecuente en los sitios cerámicos posteriores del área, cuya supervivencia en estos suelos muy húmedos se relaciona con la carbonización de sus paredes, que alcanzan $2 \mathrm{~mm}$ de espesor (Loponte 2008).

\section{Discusión}

El contexto arqueológico del nivel IV de ILS1 corresponde a uno o varios campamentos de grupos cazadores-recolectores de finales del III mileno AP. Dadas algunas especies identificadas en este nivel, la ocupación incluyó como mínimo una estación estival. Una serie de rasgos presentes en el sitio, como la gran cantidad y variedad de la fauna, las regiones anatómicas reconocidas de los peces y de las grandes presas, las evidencias de consumo y la manufactura de instrumentos óseos de diferente tipología, sugieren que se trata de un campamento base donde se desarrollaron actividades múltiples. Ambos fechados radiocarbónicos, obtenidos con muestras procedentes del techo y de la base del nivel IV, sugieren que este conjunto se depositó como consecuencia de un evento central de descarte o de varios escasamente separados en el tiempo. También son concurrentes en este sentido, la distribución vertical unimodal de las partículas arqueológicas, la no detección de episodios erosivos que hubieran mezclado eventuales y distintos sucesos de descarte separados significativamente en el 
tiempo, la ausencia de lentes estériles de materiales, el estado uniforme de meteorización de la fauna y la equivalencia estilística de los cabezales de arpón ${ }^{12}$, para los cuales comienza a evidenciarse variaciones morfométricas témporo-espaciales (Buc y Silvestre 2011). Por todo ello, es factible considerar que el nivel IV debe considerarse no solo como una unidad agregativa ( $c f$. Mengoni Goñalons 1999), sino también como un campamento base, o varios efectuados con escasa separación de tiempo, que probablemente tuvieron cierta estabilidad (cf.Lafón 1971; Pérez Jimeno 2001; Surovell 2003; Surovell et al. 2005).

Algunos autores sugirieron que los depósitosarqueológicos de la regiónson consecuencia de ocupaciones prolongadas (i.e.Torres 1911, Caggiano 1984, Politis 1988). Estas ideas estaban basadas particularmente en la presencia de áreas formales de inhumación y abundante cerámica, pero no se desarrolló una discusión explícita al respecto.Hoy disponemos de estudios estilísticos intradepósitos y notables evidencias de remontaje que sustentan eventos centrales de descarte como origen principal de una fracción de los depósitos arqueológicos de la margen derecha del río Paraná. También se ha avanzado en la identificación de cementerios utilizados durante generaciones (Loponte 2008; Mazza y Loponte 2012). Sumado a ello, los procesos de estabilización de los grupos humanos de la fase final del Holoceno tardío en determinadas áreas del humedal del Paraná inferior, ha comenzado a ser discutido en base a la identificación de conductas concurrentes. Estas incumben aspectos organizacionales complejos que necesariamente requieren estabilidad no sólo residencial, sino también dentro del paisaje, y que incluyen además de la estructuración del espacio mortuorio y el uso de gran cantidad de equipo no transportable, cierto grado de almacenamiento con consumo diferido, acopio de un excedente destinado a un intercambio mediatizado a través de alianzas y mecanismos de cooperación más o menos estables en el tiempo, y la generación de paisajes antropizados destinados a aumentar la oferta de los recursos dentro de un territorio. Estas propiedades, como ya hemos señalado anteriormente, incluyeron el desarrollo de una estrategia basada en campamentos centrales de alta estabilidad, asociado a rangos de explotación extendidos mediante el uso de dispositivos de navegación (Loponte 2008; Mazza y Loponte 2012).

La cronología del nivel IV del sitio ILS1, nos permite explorar algunas conductas previas al paquete de rasgos anteriormente enunciado, pero dado lo limitado del muestreo, necesariamente la información recuperada puede reflejar un extremo de la distribución de las conductas de principios del III milenio AP. Una de las primeras diferencias sustanciales es la falta de cerámica. Esto parece haber impactado en algunas decisiones respecto al transporte de algunas presas. La casi total ausencia de elementos craneanos de los peces sugiere su descarte en los lugares de obtención (Cione y Tonni 1978), con excepción de los cráneos de los grandes ictiófagos. Esto podría relacionarse con la imposibilidad del hervido, técnica indispensable si se pretenden extraer en forma eficiente los nutrientes del cráneo de $P$. ganulosus y de la mayoría de los Siluriformes y Characiformes del sistema fluvial del Paraná (Acosta 2005; Musali 2010). Por el contrario, en los sitios que poseen recipientes de cerámica ubicados en la margen derecha del Paraná y del río Uruguay inferior, los densos cráneos de los Siluriformes no sólo son muy abundantes, sino que han sido intensamente fragmentados (Acosta 2005; Loponte 2008; Musali 2010; Arrizurieta et al. 2010a). Esta es una de las primeras diferencias sustanciales en las estrategias de explotación y aprovechamiento de los peces entre los sitios con y sin cerámica, reforzando aún más la idea de que la adopción de la alfarería en el área tiene una directa vinculación con el proceso de intensificación en la explotación del ambiente, y que se transformará en un equipo central de la organización económica de los grupos humanos de la fase final del Holoceno tardío. 
La gran cantidad de vértebras identificadas a nivel Actinopterygii no guardan relación con la escasa cantidad de espinas de los Siluriformes identificados. Esto es una potencial evidencia de la existencia de Characiformes, y específicamente del sábalo (Prochilodus linea$t u s)$, especie que constituye el $50 \%$ de la biomasa ícticadel Paraná y cuya detección en los conjuntos arqueológicos locales a ojo desnudo es limitada, por lo que se requiere el análisis del patrón de osificación de las miles de vértebras clasificadas como Actinopterygii mediante rayos X (Loponte 2008; Loponte et al. 2009; Musali 2010).

Todas las especies de peces identificadas son estenohalinas. Esto señala que para principios del III milenio las áreas de captura tenían características oligohalinas similares a las actuales. Los peces en general son de dimensiones medianas y grandes en términos nominales. Cione y Tonni (1978) consideraron que aproximadamente el 98\% de los ejemplares se encuentran por encima de una longitud de $30 \mathrm{~cm}$. Nuevos estudios en curso que incorporan ecuaciones alométricas previamente obtenidas ( $c f$. Loponte et al. 2010b), permitirán en el corto plazo precisar las tallas de captura. La ausencia en términos significativos de peces de tallas pequeñas, como por el contrario sí sucede en algunos sitios más tardíos del área, podría relacionarse con una menor presión en la pesca, lo cual sería coherente con un ambiente donde el proceso de intensificación es comparativamente menor que el que se registra en el área durante la fase final del Holoceno tardío. Paralelamente, la incidencia de los peces del conjunto del nivel IV de ILS1, se ubica armónicamente en la tendencia temporal de explotación de este recurso, señalando que las adaptaciones fluviolacustres oligohalinas estaban bien establecidas a principios del III milenio AP, pero que aún distan de los altos valores de dependencia de la pesca que, como tendencia, muestran los contextos más tardíos de la región (ver figura 11).

Los valores precedentes sobre la incidencia de los peces en los conjuntos faunísticos, pueden explorarse relacionándolos con las variaciones culturales. Dentro del bloque cronológico correspondiente al final del Holoceno tardío, se identificaron dos clusters que se solapan temporal y espacialmente en la margen derecha delrío Paraná inferior y el estuario occidental del Río de la Plata. Estas diferencias incluyen covariaciones en algunas propiedades del registro. Uno de estos paquetes de rasgos presenta mayor incidencia de los peces, mayor grado de fragmentación de los ungulados, el empleo de tembetás en forma de $\mathrm{T}$, escaso a nulo uso de materia prima lítica yla manufactura y empleo de cerámica lisa. Su distribución abarca desde el curso inferior del río Uruguay hasta la costa occidental del río Paraná inferior hasta el estuario intermediodel Río de la Plata. El otro grupo exhibe valores más bajos en las dos primeras propiedades, ausencia de tembetás en forma de $\mathrm{T}$, probable uso de botones labiales o circulares de cerámica o hueso, el empleo de mayor cantidad de artefactos líticos esencialmente confeccionados con rocas provenientes del interior de la región pampeana, y el uso de una cerámica profusamente decorada, cuyo estilo posee un bauplan particular que tiene además un claro vector temporal (Loponte 2008). Este segundo grupo se distribuye en la costa occidental del río Paraná inferior y el estuario del Río de la Plata, sin que aún se haya identificado en el Delta medio-inferior o en la costa inferior del río Uruguay. Esta clasificación no tiene una correlación directa con las categorías históricoculturales o etnográficas que se aplican parael área y que utilizan casi exclusivamente un criterio basado en el estilo de la cerámica y/o la presencia de modelados zoomorfos (i.e. Lothrop 1932; Caggiano 1984; Bonomo et al. 2011) ${ }^{13}$. Existen evidencias que señalan que estos dos paquetes de rasgos que ya estaban en pleno desarrollo alrededor de 1100-1700 años $\mathrm{C}^{14} \mathrm{AP}$ (Loponte 2008), pueden rastrearse hacia mediados del Holoceno tardío. En efecto, los nuevos datos publicados del sitio Playa Mansa (Acosta et al. 2010a; Sartori y Colasurdo 


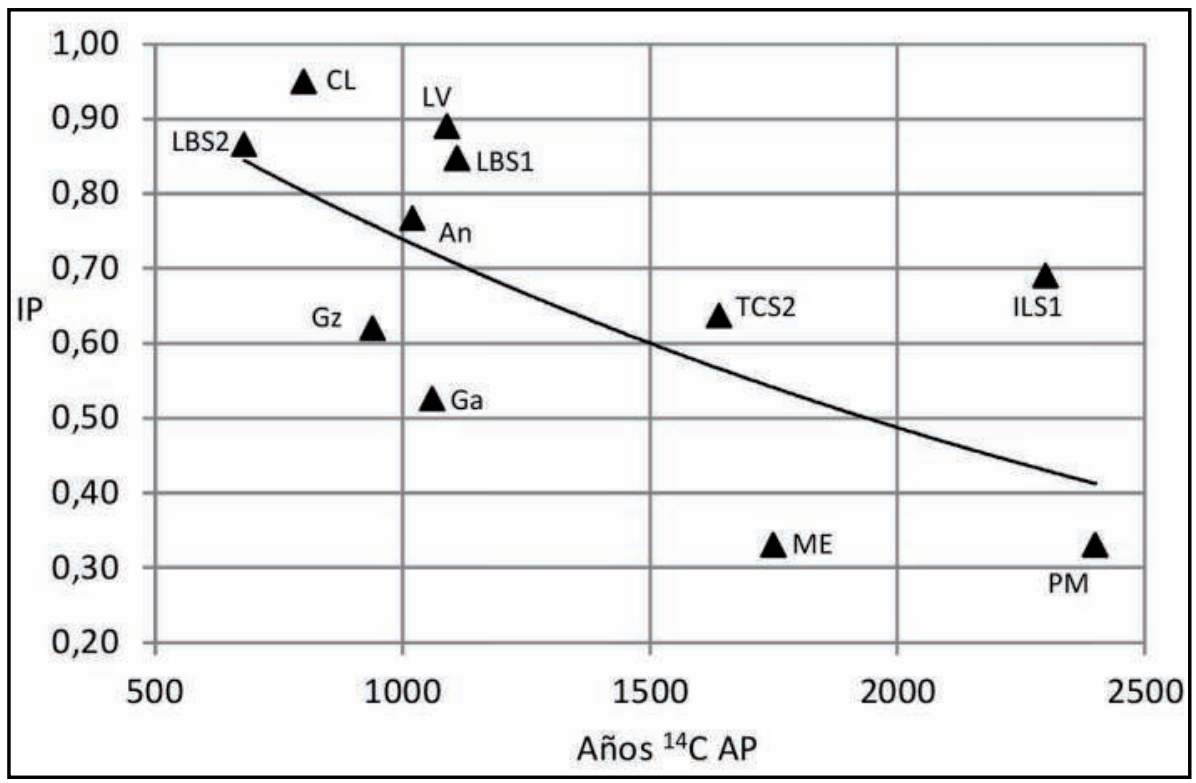

Figura 11. Cronología de los conjuntos del Holoceno tardío del humedal del Paraná inferior que poseen un índice de peces calculado. Sitios Playa Mansa (PM); Isla Lechiguanas 1, nivel IV (ILS1); Médanos de Escobar (ME); Túmulo de Campana sitio 2 (TCS2); Garín (Ga); Guazunambí (Gz); Anahí (An); La Bellaca sitio 1 (LBS1);

Las Vizcacheras (LV); Cerro Lutz (CL) y La Bellaca sitio 2 (LBS2). Datos tomados de Loponte (2008), Acosta et al.(2010b, 2011a), Arrizurieta et al.(2010a).

2011; Coll 2011), muestra un contexto que claramente puede asociarse al segundo paquete de rasgos, que se vincula claramente con la costa occidental del Paraná, del Río de la Plata y el borde oriental de la Pampa Ondulada.

Uno problema esperable que surge al rastrear en el tiempo ambos paquetes de rasgos, es que estos son operativos dentro de un bloque espacio temporal determinado. En el caso del nivel IV de ILS1, la ausencia de cerámica impide analizar algunas de las propiedades que sirven para diferenciarlos como el uso de la decoración en la cerámica o el índice de fragmentación de presas, ya que esta es una propiedad estrechamente vinculada con el uso de la alfarería (y también con factores tafonómicos que aún deben ser calibrados). Otro de los rasgos discriminantes, la presencia de tipos de tembetás, claramente es dependiente del tamaño de la muestra, por lo que aún se requiere ampliar la superficie excavada y aún eventualmente este artefacto puede tener un vector temporal en su uso que desconocemos. Otra de las propiedades diferenciales entre ambos paquetes de rasgos es el empleo de materias primas líticas, que en el caso del nivel IV de ILS1 es nula ${ }^{14}$. En las excavaciones más amplias desarrolladas por Caggiano (1977) en este nivel, tampoco se identificaron artefactos líticos, lo que sumado a la importancia de los peces dentro del conjunto, su cronología y su ubicación en el área de distribución que por el momento es exclusiva del primer grupo, sugiere que tentativamente puede ser considerado dentro de este linaje, en un estadio evolutivo anterior (ver figura 12).

Respecto de la explotación terrestre, el taxón de mayor importancia en términos de biomasa dentro del conjunto de ILS1 es B. dichotomus. Los machos de este mamífero alcanza 
regularmente $150 \mathrm{~kg}$ de peso, constituyendo la segunda presa con mejor ranking en el área, luego de los peces migradores del sistema fluvial local (cf. Loponte 2008). Si bien aún no contamos con valores de fragmentación de su sistema esquelético, el conjunto presenta grandes porciones de elementos óseos con negativos de impacto, sugiriendo una conducta destinada a la extracción de la médula, pero no de hervido, como sucede en los sitios más tardío del área, cuyas astillas muestran promedios que oscilan según los sitios entre 4 y 6 $\mathrm{cm}$ (Acosta 2005).

El segundo mamífero importante en términos de biomasa dentro del conjunto es $M$. coypus. Si bien los valores de NISP son los más altos con excepción de los peces, el peso de 30 ejemplares de tamaño mediano a grande de este roedor equivale a un solo ciervo de los pantanos. Dentro del contexto de la arqueología del área, se debe considerar que el coipo tiene un valor adicional, dado que es la única especie peletera de calidad ${ }^{15}$, lo que sin duda contribuyó a aumentar su ranking como presa (Loponte 2008). A diferencia de lo que sucede en los conjuntos más tardíos del área que tienen cerámica, los restos óseos de este mamífero se encuentran con un grado de fragmentación nominalmente más bajo, siendo frecuente la recuperación de elementos óseos completos (ver también Caggiano 1977). Esto contrasta en alguna medida con el registro de los sitios más tardíos del área que tienen cerámica, lo que refuerza la hipótesis que su fragmentación tuvo por objeto la extracción de nutrientes mediante el hervido (Acosta 2005, Loponte 2008).

De una manera similar a lo observado enlos conjuntos arqueofaunísticos más tardíos del área, H. hydrochaeris se encuentra muy poco representado, lo cual también fue advertido por Cione y Tonni (1978) en la colección obtenida por Caggiano (1977). En los sitios del área, ubicados en la fase final del Holoceno reciente, se recuperan preferentemente elementos el

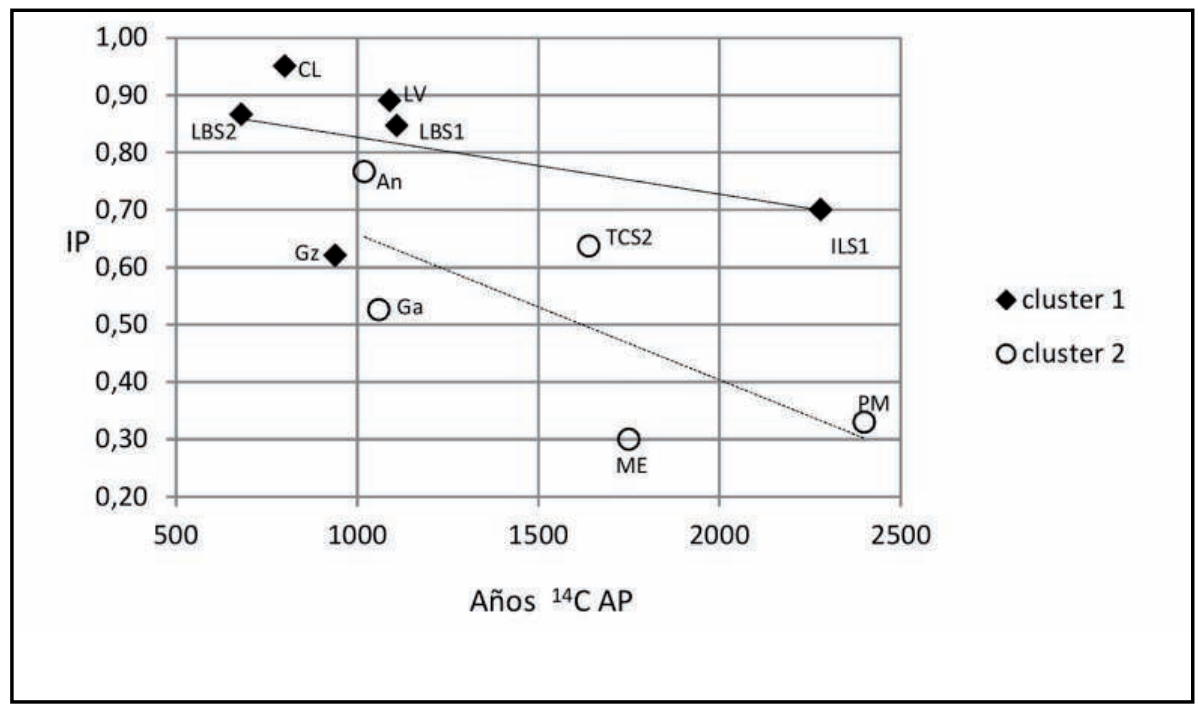

Figura 12. Isla Lechiguanas 1. Variaciones temporales del índice de peces según losclusters definidos en el área. Sitios correspondientes alcluster 1 son: La Bellaca sitio 1 (LBS1), La Bellaca sitio 2 (LBS2), Guazunambí (Gz), Las Vizcacheras (LV), Isla Lechiguanas sitio 1, nivel IV (ILS1) y Cerro Lutz (CL). Cluster 2: Garín (Ga), Anahí (An), Túmulo de Campana sitio 2 (TCS2), Médanos de Escobar (ME) y Playa Mansa (PM) (cf. Loponte 2008; Acosta et al. 2010b, 2011a; Arrizurieta et al. 2010a). 
autopodio, como también sucede en el nivel IV del ILS1. Su baja frecuencia, que contrasta con su alto ranking como presa potencial (Loponte 2008), no puede relacionarse con eventuales impedimentos de los sistemas de armas o con condiciones ambientales diferentes a las actuales, ya que la biocenosis recuperada en el nivel IV sugiere un clima similar al actual. Debido a su escasa presencia y la particular representación anatómica reconocida en los conjuntos arqueofaunísticos, ha sido considerado como un taxón tabú (Acosta 2005; Loponte 2008). Esta idea tiene un correlato en el contexto de Arroyo Fredes, que es de origen guaraní, y que posee un paquete de rasgos completamente diferentes a los sitios de los cazadores-recolectores del área. En el conjunto faunístico de este sitio, el carpincho es la segunda especie en importancia, demostrando su alta disponibilidad ambiental durante el Holoceno reciente (Loponte y Acosta 2003-2005; Acosta y Mucciolo 2009).

Dentro del conjunto de ILS1 podemos analizar otras conductas de explotación faunística que ya son visibles y que se repiten en todos los contextos cerámicos de la región, como la explotación de L. guanicoe. Sabemos que los grupos cazadores-recolectores muy móviles de la llanura interior de la Pampa Ondulada, que se desarrolla a partir de la margen derecha del Paraná, tenían su subsistencia basada en este camélido. Los análisis de los sitios Hunter (1990 \pm 40 años $C^{14}$ AP; 1855 - 2021 años cal. AP $( \pm 2$ s) (Beta 284161) y Meguay (1120 \pm 20 años $C^{14}$ AP; 855 - 975 años cal. AP)(UGAMS 3301) son contundentes al respecto (Loponte et al. 2010a; Loponte 2012).También sabemos que esta explotación alcanzó los siglos XIV$\mathrm{XV}$, ya que dos fechados realizados directamente sobre huesos de L. guanicoe (escápula y metapodio) procedentes de materiales de colección, catalogados del sitio Cañada de Rocha, arrojaron fechas taxón de $540 \pm 40$ años $C^{14}$ AP (Beta 220693) y $560 \pm 40$ años $C^{14}$ AP (Beta 220695). La antigüedad referida corresponde al intervalo 1390 - 1420 años cal. AP (Toledo 2010). Los grupos aborígenes que se asentaron en la margen derecha del Paraná inferior, dentro del bloque 2400 - 600 años AP, cazaron este camélido y/o lo obtuvieron por intercambio con estos grupos de la llanura, ingresando preferentemente sus pieles; así probablemente ingresaron adheridas las falanges y pequeños fragmentos distales de los metapodios que no inciden en el peso de acarreo, y que son los elementos óseos más recurrentes de los sitios de la margen derecha del Paraná (Loponte 1996-1998; Loponte et al. 2004) ${ }^{16}$. En algunos sitios el ingreso del guanaco fue más completo, ya que en Río Luján se identificó un molar (Salemme, 1987) y en Playa Mansa una rótula que fue fechada (Acosta et al. 2010b), además de un fragmento de metatarso proximal y un calcáneo (Sartori y Colasurdo 2011). Esto implica no solo el ingreso del autopodio, sino también del zeugopodio y del cráneo o la mandíbula (ver también Loponte 2012). La presencia de dos falanges de L. guanicoe y un gran fragmento de metapodio distal con un negativo de impacto en el nivel IV de ILS1, señalan que esta conducta de caza logística en la Pampa Ondulada y/o intercambio con los grupos aborígenes de la margen derecha del Paraná y/o del interior de la llanura pampeana ya estaba en práctica a principios del III milenio $\mathrm{AP}^{17}$.

Otra evidencia de explotación logística es la presencia de O. bezoarticus que no habita en las áreas insulares, pero que probablemente penetró en el paisaje fragmentado de los Bajíos Ribereños y el bosque xeromórfico continental de la margen derecha del Paraná (Acosta 2005; Loponte 2008). La cantidad de restos óseos identificadosde este cérvido es pequeña. Algo similar fue observado por Cione y Tonni (1978), quienes reconocieron un cérvido de tamaño pequeño que podría corresponder a este mamífero o a Mazama goauzoubira. En la muestra disponible se identificaron huesos de los quiridios, lo que también indica una secuencia de desarticulación fuera de los campamentos y probablemente un acarreo que incluyó un trayecto terrestre. En otros sitios del área, influenciados por su insularidad, la 
representación del venado es nula otambién es muy baja, y en este último caso también tiende a concentrarse igualmente en los quiridios (Bogan 2005; Acosta y Mucciolo 2009).

Otra especie típica de la llanura y ausente en las islas, Rhea americana, no está incluida dentro del conjunto obtenido en la temporada de excavación de 2011, y tampoco fue identificada en los materiales recuperados por Caggiano ( $c f$. Cione y Tonni 1978). Desde hace varios años se sabe que la representación del ñandú en los sitios de la margen occidental del Paraná (Bajíos Ribereños) se concentra exclusivamente en falanges y extremos distales del tarso, faltando por el momento otros elementos óseos como así también las cáscaras de huevo (Acosta 2005; Loponte 2008). Algunos autores consideran que “... la baja representación o ausencia de ñandú en los tres sectores estudiados sigue la misma tendencia observada en el resto de la región pampeana para el Holoceno tardío" (Politis y León 2010:72). Sin embargo, no es correcto considerar que existan registros equivalentes en los Bajíos Ribereños, que es uno de los tres sectores que alude Politis y León, y el resto de la región pampeana. En los sitios del sur de esta llanura, la representación ósea, si bien es baja, incluye tibia-tarsos, mandíbulas, fémures y húmeros, además de cáscaras de huevo (ver un resumen en Frontini y Picaso 2010). En la Pampa Ondulada, la representación incluye falanges, tarso-metatarsos y tibia-tarsos, además de cáscaras de huevo (Loponte 2012). Es decir, una representación si bien fragmentada, sustancialmente más completa que aquella que se observa en el humedal del Paraná inferior. Este dato no es menor, porque la ausencia de cáscaras de huevo, entre otras cosas, indica que las nidadas probablemente estaban fuera del valle de inundación del río Paraná/Bajíos Ribereños, y por lo tanto, esta especie podría haber sido logísticamente cazada en el borde oriental de la Pampa Ondulada. Otra opción es considerar que algunos ejemplares ingresaron esporádicamente en el valle de inundación del río Paraná y su captura fue ocasional. Sin embargo, la representación comprende solo falanges y tarsos-metatarsos distales frente por ejemplo, a la presencia de tarsos-metatarsos proximales y tibia-tarsos en la Pampa Ondulada o la sustancialmente más completa representación que se observa en la Pampa Austral. El aumento de las muestras permitirá ampliar esta discusión en el futuro inmediato.

En su conjunto, la colección faunística de ILS1 muestra una oferta natural similar a la actual. Los peces identificados son estenohalinos de aguas cálidas, cuyos patrones migratorios requieren rangos determinados de la temperatura del agua, además de parámetros estables en las variaciones térmicas (Oldani 1990). Otro taxón reconocido, B. dichotomus, también requiere parámetros ecológicos muy precisos vinculados con el ambiente subtropical, el desarrollo de praderas inundables y la presencia de una cobertura vegetal alta (ver un resumen en Loponte 2004). Dentro de este cuadro, debemos agregar la identificación de S. romanzoffiana, una palmera de distribución mesopotámica, cuyas poblaciones decrecen en densidad de norte a sur, siguiendo un vector térmico (Báez 1937; Cabrera y Zardini 1978). Sabemos que esta palmera ya era explotada por el hombre en el estuario intermedio del Río de la Plata para principios del V mileno AP (Beovide 2011). Esto señala una larga interrelación entre el pindó y los humanos en el tramo inferior de la Cuenca del Plata, conducta que por el momento, encuentra en el nivel IV de ILS1 su registro más antiguo en el Paraná inferior. No tenemos evidencias de manipulación de otros vegetales, pero en el registro del estuario intermedio del Río de la Plata se identificaron especies manipuladas o tal vez domesticadas para el V milenio, y vegetales cultivados para el IV milenio AP (Beovide 2011).

En términos comparativos, las condiciones ambientales requeridas por labiocenosis recuperada en ILS1 no difiere de aquellas registradas en los sitios del área insular del Delta 
medio y de la margen derecha del río Paraná, cronológicamente ubicados entre 1700 y 400 años $C^{14} \mathrm{AP}$ (Loponte 2008; Acosta et al. 2011a; Arrizurieta et al. 2010a). Este cúmulo de datos sugiere que la oferta natural se estableció como mínimo en el inicio del Holoceno tardío, tal vez cuando la disminución del nivel marino y el aumento de las precipitaciones en las cabeceras del río Paraná (Cavallotto et al. 1999, 2004; Violante y Parker 2004) desplazaron aguas abajo la zona de máximo gradiente salino, cambiando las condiciones ambientales de estuáricas a netamente fluviales. Esto además permitió que las especies estenohalinas más importantes de la cuenca (e.g. P. lineatus, P. granlosus) extendieran gradualmente sus patrones de migración hasta alcanzar el Paraná-Uruguay inferior y el sector superior del estuario del Río de la Plata, estableciendo la oferta sobre la cual se desarrollarán las economías humanas del Holoceno tardío.

Finalmente, uno de los aspectos más notables del nivel IV de ILS1 es la ausencia de cerámica en un conjunto cuyos dos fechados que se superponen, abarcan el bloque 2190 $2364( \pm 2 \sigma)$ años $C^{14} \mathrm{AP}$, cuando en la margen derecha del río Paraná, una cerámica muy bien elaborada y profusamente decorada (Coll 2011) ya estaba en uso en el sitio Playa Mansa, dentro del rango temporal 2360 - 2440 a. $C^{14}$ AP (Acosta et al. 2010b). Asimismo, en la margen oriental del estuario intermedio de Río de la Plata, se identificaron contextos con producción de cerámica fechados en 4800 años $C^{14}$ AP (Beovide 2011). Estos fechados efectuados sobre contextos asociados a la cerámica, se han visto confirmados por fechados directos realizados sobre la misma cerámica (Beovide, com. pers. 2012). De esta forma, la alfarería ya se manufacturaba en la región en el momento en que se generó el nivel IV, donde sin embargo, no se ha identificado un solo fragmento. Aquí pueden introducirse múltiples aspectos para discutir, que incluyen desde una eventual contaminación y consecuente rejuvenecimiento de los fechados del nivel IV de ILS1, variabilidad funcional de los sitios, hasta procesos diferenciales de adopción en el uso de la cerámica según distintos linajes arqueológicos. Respecto de la primera opción, sabemos que la ictiofauna estenohalina identificada en el nivel IV y al altura del sitio sobre el nivel del mar, introduce un rango máximo de ocupación aproximado de 3500 a. $\mathrm{C}^{14}$ AP para este conjunto. Nuevos fechados en curso permitirán ampliar la discusión sobre este aspecto. En relación a la variabilidad funcional, esta opción parece poco probable, ya que contexto arqueológico sugiere que se trata de un campamento base donde se esperaría el uso de la cerámica. La tercera opción constituye una nueva vía de análisis que necesita incorporar nueva información. Por el momento, estas tres opciones entre otras, están abiertas y se requieren nuevos fechados y muestreos regionales de sitios del III y IV milenio para avanzar en la discusión sobre el proceso de adopción de la cerámica en la región.

\section{Conclusiones}

El contexto recuperado en el nivel IV de ILS1 se generó como consecuencia de uno o de varios campamentos base de grupos cazadores-recolectores durante el bloque cronológico 2190 - 2364 años $C^{14}$ AP. Nuevos fechados radiocarbónicos en curso permitirán discutir si existe algún tipo de contaminación y eventual rejuvenecimiento de las edades obtenidas.

Durante la ocupación no se utilizó cerámica. Las propiedades del registro faunístico son coherentes con un procesamiento de la fauna que excluye el hervido. No se puede precisar si esta ausencia obedece a la falta de esta tecnología o a un aspecto vinculado con la variabilidad del sistema de asentamiento-subsistencia. 
La ocupación humana se efectuó cuando los grupos cazadores-recolectores ya utilizan dispositivos de navegación, lo que probablemente les permitió desarrollar rangos extendidos de caza, recolección e intercambio. Ello puede explicar el ingreso al campamento de presas superiores a los $100 \mathrm{~kg}$ de peso dentro de un ambiente fluvialmente fragmentado. La existencia de rangos de acción extendidos, empero, no parecen haber incluido redes de intercambio de bienes alóctonos, ya que no se reconocen en el sitio las cuentas de malaquita comunes en los sitios más tardíos de la región. Esta ausencia también podría relacionarse con la falta de circulación de estos bienes suntuarios durante principios del III milenio en el sector insular del Delta medio. Sin embargo, para determinarlo se requiere una mejor calidad del muestreo.

La explotación faunística estuvo centrada en los recursos de alto ranking del área fluviolacustre: los peces estenohalinos con patrones de migración estival, $B$. dichotomus y $M$. coypus. Por el contrario, aquellos de más baja jerarquía no han sido explotados o lo fueron de una manera muy marginal (i.e. Diplodon sp., Cavia aperea). Los peces, particularmente $P$. granulosus ingresaron sin el cráneo, lo cual constituye una de las primeras diferencias en las estrategias de explotación de este recurso respecto a los sitios que poseen cerámica.Tanto el ciervo de los pantanos como el coipo ingresaron completos al sitio, o con una completitud nominalmente alta.

Si bien el rango de acción incluyó el sector continental bonaerense, los recursos típicos de la llanura pampeana como el guanaco y el venado de las pampas tuvieron una contribución marginal en la dieta, por lo que tal vez otros aspectos incidieron en la toma de decisiones relacionadas con su explotación, tal como el acopio de pieles de gran tamaño y flexibilidad como aquella que provee el guanaco y formas base para la confección de artefactos. Tampoco puede excluirse que estas pieles hayan ingresado por mecanismos de intercambio, aunque como hemos mencionado, no existen otras evidencias en este sentido como materias primas líticas u objetos suntuarios alóctonos.La casi total ausencia de restos de H. hydrochaeris dentro de un ambiente que es su hábitat, y que como presa tuvo un ranking elevado debido a su tamaño y conductas de agregación (Loponte 2008), sugiere que la excepción de su consumo, probablemente de origen simbólico, ya estaba establecida hacia finales del III milenio AP.

En el nivel IV de ILS1 se consumió S. romanzoffiana, constituyendo el indicio más antiguo del humedal del Paraná inferior donde se verifica la manipulación de estas palmeras. La cantidad recuperada por el momento es pequeña comparada con la observada en los sitios más tardíos de la región, pero constituye por el momento el único indicio de la ingesta de alimentos vegetales. En su conjunto, la biocenosis recuperada del nivel IV es similar a actual. Esto refuerza la hipótesis de que el humedal del Paraná inferior tuvo un alto poder de resiliencia a lo largo del Holoceno tardío, y que este aspecto influyó probablemente como un componente más en la jerarquización de este paisaje por parte de los grupos humanos.

La ausencia de materias primas líticas no parece relacionarse con un defecto del muestreo, sino más bien constituye una propiedad del registro. En este sentido, la materia prima básica para la conformación de instrumentos fue el asta y el hueso, es decir, materia prima local. El uso de redes de pesca y de arpones señala el desarrollo de un paquete tecnológico específico y claramente adaptado al sistema fluvial pulsátil del Paraná. Esto demuestra un conocimiento acabado de los comportamientos de las diferentes especies de peces de la baja cuenca del Paraná-Plata. Laidentificación de cabezales de arpón en el nivel IV constituye por el momento el registro más antiguo de estos dispositivos en la cuenca inferior de los ríos Paraná y Uruguay. 
En su conjunto, el nivel IV del ILS1 señala la presencia de grupos cazadores-recolectores adaptados a los recursos fluvio-lacustres de características oligohalinas, quienes utilizaron dispositivos de navegación y un equipo de subsistencia confeccionado con materias primas locales, donde la pesca y la caza de recursos fluviolacustres de alta jerarquía constituyeron una de las bases de la economía aborigen. Este paquete de rasgos que se presenta bien desarrollado durante mediados del Holoceno tardío, tiene probablemente su origen durante la transición del Holoceno medio al tardío, cuando las condiciones estuáricas cambian a fluviales y se conforma un paisaje fluvial similar al actual, con emergencia de un paisaje insular vinculado con los proceso de progradación del Delta. La ampliación de las excavaciones de ILS1, el análisis con mayor grado de detalle del registro recuperado, junto con aquel obtenido del nivel cerámico de este mismo depósito y de otros cercanos que presentan rasgos diferentes, nos permitirá avanzar con mayor precisión en el estudio de la evolución de los diferentes linajes culturales del área.

\section{Agradecimientos}

A la Municipalidad de Ibicuy y al Sr. Alberto Spegazzini, dueño del predio donde se encuentra el sitio por la excelente predisposición y ayuda recibida.A la Dra. Amanda Caggiano por su ayuda para que pudiéramos llegar al sitio y por el préstamo para su estudio de los materiales recuperados durante las excavaciones que llevara a cabo en este sitio. A los profesores de la escuela agrícola de Ibicuy Alberto Oronó y Alberto "Pichy" Fernández por su inestimable apoyo para el desarrollo de las tareas de campo. A los evaluadores del artículo, que han introducido comentarios muy valiosos. La responsabilidad de lo vertido es de los autores.

\section{Notas}

${ }^{1}$ La ubicación de los sitios de la costa norte bonaerense es aproximada, dado la escala del mapa. Desde hace unos años, desaconsejamos la ubicación exacta de los sitios fácilmente accesibles y sin vigilancia, como los del tramo inferior del río Areco, debido a que estos sitios son catalogados de "muy vulnerables", ya que están en terrenos fiscales, no tienen vigilancia y son fácilmente accesibles por caminos cercanos. La ubicación mediante GPS recientemente publicada de estos sitios (Lanzelotti et al. 2011), lo torna aún más vulnerables. Por el contrario, aquellos que tienen escalas adecuadas de mapas y que son ubicados con precisión, incluyendo ubicación con GPS, como el que presentamos aquí, son los que están en terrenos privados, sujetos a controles de acceso.

${ }^{2}$ En el estuario del Arroyo Las Hermanas, Partido de Ramallo, bajo 2,5 m de sedimento aluvial se identificaron restos de un gran cetáceo con posibles huellas de corte asociados con lascas de cuarcita y calcedonia que está siendo actualmente excavado y que representaría un evento de aprovechamiento de fauna marina. Los fechados radiocarbónicos están en proceso de análisis.

${ }^{3}$ Los sitios publicados son Garín, Anahí, Las Vizcacheras, Túmulo de Campana sitio 2, Arroyo Sarandí, Arroyo Guazunambí, La Bellaca sitio 1, La Bellaca sitio 2, Playa Mansa y Cerro Lutz. Médanos de Escobar fue presentado recientemente pero aún permanece inédito. Otros 14 sitios de la región se hallan en distintas etapas de investigación y elaboración de datos. Por su parte, algunos de los sitios clásicos del área como Río Luján y Cañada Honda, poseen registros publicados con diferentes sesgos no calibrados, pero que en caso de Río Luján sin duda implican la pérdida selectiva de material (ver Loponte 2008), del mismo modo que la colección museológica del sitio Cañada Honda.

${ }^{4}$ Las investigaciones se desarrollan también con la inestimable y necesaria colaboración de todos los otros equipos que trabajan en el Paraná medio e inferior en arqueología prehispánica, con alguna excepción. 
${ }^{5}$ Lanzelotti y colaboradores (Lanzelotti 2011), consideran que el contexto del "sitio 1 de Cañada Honda" sugiere que "... para ca. 2100 AP podrían ya haber existido los patrones de adaptación al ambiente litoral, con explotación de recursos acuáticos tales como el coipo y varias especies de peces" (Lanzelotti et al: 2011:359). Sin embargo, con alguna anterioridad, ya se había determinado la existencia de adaptaciones a la explotación de recursos fluviales en Playa Mansa, cuyo contexto es varios siglos anterior al fechado de dos huesos provenientes de la colección museológica excavada a mediados del siglo pasado por personal del Museo de Mercedes (para más detalles, ver Acosta et al. 2010b; Sartori y Colasurdo 2011).

${ }^{6}$ La densidad de fragmentos cerámicos fue calculada en relación al volumen excavado del nivel II, y no como se han realizado para otros sitios con gran cantidad de cerámica, efectuados en base a los metros cuadrados (por ejemplo Politis 2005), ya que esto genera una magnitud que no permite la comparación entre diferentes depósitos, ya que estos poseen una tercera dimensión, que es obviamente la profundidad.

${ }^{7}$ Las calibraciones se efectuaron mediante el programa OxCal 4.1, curva de calibración para el hemisferio sur ShCal04.

${ }^{8}$ Excepto en la pared Este de la cuadrícula 2, donde se distinguieron dos pequeños lentes arenosos (entre 2 y $3 \mathrm{~cm}$ de potencia).

${ }^{9}$ En la excavación de 2011 se empleó una malla de $5 \mathrm{~mm}$ y luego cernido en húmedo con malla de $1 \mathrm{~mm}$ (para más detalle ver Loponte 2008).

${ }^{10}$ Están excluidos de este cómputo los fragmentos no identificables menores a $1 \mathrm{~cm}$.

${ }^{11}$ Existen varias maneras de calcular índices de riqueza, como así también hay diferentes índices disponibles en la bibliografía zooarqueológica, algunos más clásicos (Broughton 1994) y otros más recientes (Butler 2000; Lyman 2003). No todos, obviamente, son equivalentes. Lo significativo en la construcción de los mismos es que ilustren el proceso o las propiedades que se requieran visualizar. En este caso, el índice utilizado aquí mide adecuadamente la incidencia de los valores de NISP de los peces frente a los mamíferos en un valor que oscila entre 0 y 1 , siendo este último valor representativo de un conjunto conformado solo por restos de peces, mientras que el valor 0 corresponde a una colección que carece totalmente de ellos. Un desarrollo del mismo puede verse en Loponte (2008).

${ }^{12}$ Lanzelotti, Politis y colaboradores (Lanzelotti et al. 2011) han simplificado, y de esta manera, sesgado el concepto de penecontemporaneidad arqueológica y de las unidades agregativas de análisis que se utilizan en algunos trabajos realizados en el área, sobre todo en relación a la representatividad de los fechados radiocarbónicos, como así también a la relación entre los fechados que proceden de eventos de inhumación y los contextos arqueológicos, aspecto del cual ya existe una discusión más desarrollada, disponible en la bibliografía, aplicada con casos de estudios del área, discutida en varios trabajos, y que por lo tanto no repetiremos aquí (ver entre otros, Acosta 2005; Acosta et al. 2010c; Loponte 2008).

${ }^{13}$ Existen otros linajes arqueológicos identificados en el Delta inferior, Delta medio-superior y Planicies Inundables, cuyas propiedades están siendo elaboradas con los registros propios de esos sectores. Estos análisis demuestran una complejidad cultural muy superior a las categorías que utilizó y eventualmente sigue utilizando la arqueología histórico-cultural del área. Una visión esencialista puede verse sintetizada en los trabajos de Rodríguez (2001), pero que se siguen aplicando en otros proyectos contemporáneos del área.

${ }^{14}$ Esta es una propiedad relativamente independiente del tamaño del muestreo en los sitios del área (ver Loponte 2008).

${ }^{15}$ Los cánidos locales (Chrysocyon brachyurus y Lycalopex griseus) son también especies peleteras por excelencia, pero han sido identificados en cantidades muy pequeñas en los conjuntos faunísticos del área. 
${ }^{16}$ Politis y Pedrotta (2006) consideran la existencia de llamas (Lama glama; el énfasis es nuestro), en la Pampa Ondulada, y que este sería el origen de los restos de L. guanicoe que se detectan en el área y en los sitios de la margen derecha del río Paraná, y por lo visto también sería el caso de los restos de guanaco del nivel acerámico de ILS1, si seguimos la interpretación propuesta por estos autores. Sin embargo, como hemos visto, la llanura de la Pampa Ondulada poseía importantes poblaciones de guanacos cuando se formaron todos los depósitos del Paraná inferior que tienen restos de este camélido, aún los más tardíos. Interpretar que estos restos provienen de llamas acarreadas durante miles de kilómetros a la costa del Paraná, es por lo menos curioso. Además, la explicación de Politis y Pedrotta es no solo contraria a la explicación más parsimoniosa, sino que no tiene una sola contrastación positiva con el registro, a diferencia de la presencia de tropas de guanacos que sustentaban a los cazadores-recolectores de la Pampa Ondulada durante la fase final del Holoceno reciente. Además, ahora también sabemos que este camélido estuvo como mínimo en el área hasta los siglos XIV-XV. Es decir muy próximo con el arribo de los europeos. Todavía no tenemos fechados directos de este camélido para el siglo XVI, sencillamente porque aún no hemos detectado sitios de este período en la Pampa Ondulada. Como todo problema de muestreo, y como ya hemos visto con los fechados de Cañada de Rocha, solo hace falta tiempo e investigación.

${ }^{17}$ Cione y Tonni (1978) también identificaron restos de L. guanicoe en el nivel acerámico, pero no mencionan los elementos anatómicos recuperados.

\section{Bibliografía citada}

Acosta, A.

2005. Zooarqueología de Cazadores-Recolectores del Extremo Nororiental de la Provincia de Buenos Aires (Humedal del Río Paraná Inferior, Región Pampeana, Argentina). Tesis doctoral inédita, Facultad de Ciencias Naturales y Museo, Universidad Nacional de La Plata. La Plata.

Acosta, A., N. Buc y L. Mucciolo.

2010a. Linking Evidences: from Carcass Processing to Bone Technology.The Case of the Lower Paraná Wetlands (Late Holocene, Argentina). Ancient and Modern Bone Artefacts from America to Russia. Cultural,technological and functional signature. Editado por A. Legrand-Pineau, I. Sidéra, N. Buc, E. David y V. Scheinsohn. BAR International Series. 2136: 303-314.

Acosta, A., N. Buc y D. Pau.

2011c. Huellas de aserrado perimetral sobre restos óseos humanos. el caso del sitio Cerro Lutz, provincia de entre ríos. Comechingonia 15: 55-69.

Acosta, A; S. Escudero, M. R. Feuillet Terzaghi, D. Loponte y L. Perez Jimeno.

2010b. Conectando registros: variabilidad arqueológica en la cuenca del Paraná. MamülMapu: pasado y presente desde la arqueología pampeana. Editado por M. Berón, L. Luna, M. Bonomo, C. Montalvo, C. Aranda y M. Carrera Aizpitarte, tomo II: 17-28. Editorial Libros del Espinillo, Ayacucho.

Acosta, A. y D. Loponte

2004.Presas y predadores: avances en la composición isotópica de la dieta de los grupos prehispánicos del sector centro-oriental de la Región Pampeana. Arqueología 12: 105-134. 
Acosta, A., D. Loponte y C. García Esponda.

2011b. Primer registro de perro doméstico prehispánico (Canis familiaris) entre los grupos cazadores recolectores del humedal de Paraná inferior (Argentina). Antípoda. Revista de Antropología y Arqueología 13: 175-199.

Acosta A., D. Loponte y J. Musali.

2007a. A Taphonomic Approach to the Ichtyoarchaeological Assemblage of La Bellaca site 2, Wetland of the Lower Paraná River, Pampean Region (Argentina). Taphonomy and Zooarchaeology in Argentina. Editadopor M. Gutiérrez, G. Barrientos, G. Mengoni, Goñalons, L. Miotti y M. Salemme, pp. 71-88. BAR International Series 1601, Oxford.

Acosta, A., Loponte, D. y P. Tchilinguirián

2011a. Nuevos aportes para la arqueología de los Bajíos Ribereños Meridionales: el sitio Médanos de Escobar. Poster presentado en el VI Congreso de Arqueología de la Región Pampeana, La Plata.

Acosta, A., y L. Mucciolo.

2009. Zooarqueología dos grupos horticultores amazónicos no rio Paraná inferior: o caso do sítio Arroyo Fredes. Revista de Arqueología 22 (1) 43 - 63.

Acosta, A.; J. Musali y J. Olub.

2007b. Pautas relacionadas con el procesamiento y consumo de peces en sitios arqueológicos del humedal del Paraná inferior. Arqueología en las Pampas. Editado por C. Bayón, A. Pupio, M. I. González, N. Flegenheimer y M. Frère, tomo II, pp. 567-590. Sociedad Argentina de Antropología. Buenos Aires.

Adams, J. M. y H. Faure.

1997. Preliminary vegetation maps of the world since the Last Glacial Maximum: An aid to archaeological understanding. Journal of Archaeological Science 24: 623-647.

Aguirre, M. L.,

1993. Palaeobiogeography of the Holocene molluscan fauna from Northeastern Buenos Aires Province, Argentina: its relation to coastal evolution and sea level changes. Palaeogeography, Palaeoclimatology, Palaeoecology 102, 1-26.

Albero, M. C. y F. E. Angiolini.

1985. Ingeis Radiocarbon Laboratory Dates II. Radiocarbon 27 (2B): 314-337.

Amestoy, F. y G. Fabiano

1992. Distribución espacio-temporal, estructura poblacional y reproducción del armado común, Pterodoras granulosus (Pisces, Doradidae), en el Río de la Plata medio e inferior y en el río Uruguay inferior. Publicaciones de la Comisión Administradora del Río Uruguay, Serie Técnico-Científica 1: 1-12

Arrizurieta, P., N. Buc, B. Mazza, L. Mucciolo, J. Musali, F. Parisi, D. Pau y M. Pérez. 2010b. Nuevos aportes a la arqueología del sector continental del humedal del Paraná inferior. Arqueología Argentina en el Bicentenario de la Revolución de Mayo. Editado por J. R. Bárcena y H. Chiavazza, tomo V, pp. 1793-1797. Zeta Editores. Mendoza. 
Arrizurieta, M. P., L. Mucciolo y J. Musali.

2010a. Análisis faunístico preliminar del sitio Cerro Lutz. Mamül Mapu: pasado y presente desde la arqueología pampeana. Editado por L. Luna, M. Bonomo, C. Montalvo, C. Aranda y M. Carrera Aizpitarte, tomo 1, pp. 261-276. Editorial Libros del Espinillo. Ayacucho.

Badone, E. y R. M. Farquhar.

1982. Application of neutron activation analysis to the study of element concentration and exchange in fossil bones.Journal of Radioanalytical Chemistry 69: 291-311.

Báez, J.R.

1937. Área de dispersión actual de las palmeras en la flora de Entre Ríos. Anales de la Sociedad Argentina de Estudios Geográficos "GEA", 5: 63-78.

Behrensmeyer, A. K. 1978.

Taphonomic and ecologic information from bone weathering. Paleobiology 4: 150-162.

Beovide, L.

2011. La presencia de cultígenos desde el quinto milenio en el registro arqueológico del curso medio platense. Revisión y proyecciones. Avances y Perspectivas en la Arqueología del Nordeste. Editado por M. R. Feuillet Terzaghi, M. B. Colasurdo, J. Sartori y S. Escudero, pp. 155-173.

Berger, R. y N. Meek.

1992. Radiocarbon dating of Anodonta in the Mojave River Basin, Radiocarbon 34 (3): 578 584.

Berón, M, y G. Politis 1997. Arqueología Pampeana en la década de los '90. Estado de las investigaciones y perspectivas. Arqueología Pampeana en la década de los '90, pp. 7-32. Museo de Historia Natural/ INCUAPA.San Rafael/Olavarría.

Bettinger, R. L., R. Malhi y H. McCarthy.

1997. Central place models of acorn and mussel processing. Journal of Archaeological Science 24 (10): 887-899.

Blau, M., Deevey Jr., E. S. y M. S. Gross.

1953. Yale natural radiocarbon measurements, I. Pyramid Valley, New Zealand and its problems. Science 118: 1 - 6.

Bogan, S.

2005. Análisis del material faunístico del sitio arqueológico Arenal central, Isla Martín García. $V I^{\circ}$ Jornadas Chivilcoyanas en Ciencias Sociales y Naturales. Centro de Estudios en Ciencias Sociales y Naturales. Edición digital. Chivilcoy.

Bonetto, A.A, Canon Verón, M. y D. Roldán.

1981. Nuevos aportes al conocimiento de las migraciones de peces en el río Paraná. Ecosur, 8(16): 29-40.

Bonomo, M., G. Politis y C. Gianotti.

2011. Montículos, jerarquía social y horticultura en las sociedades indígenas del delta del río Paraná (argentina). Latin American Antiquity: 22 (3): 297-333. 
Broecker,W. S.

1964. Radiocarbon dating: a case against the proposed link between River Mollusks and soil humus, Science 143: 596 - 597.

Broecker, W. S. y A. Walton.

1959. The Geochemistry of $\mathrm{C}^{14}$ in freshwater systems. Geochimica et Cosmochimica Acta 16: $15-38$.

Broughton, J. M.

1994. Late Holocene resource intensification in the Sacramento Valley, California: The vertebrate evidence. Journal of Archaeological Science 21:501- 514.

Brunazzo, G.

1999.Investigaciones arqueológicas en el sitio La Norma (Partido de Berisso, Provincia de Buenos Aires, Argentina). Actas del XII Congreso Nacional de Arqueología Argentina 3: 101-106. La Plata

Buc, $\mathrm{N}$.

2007. Ser o no ser: arpones y "arpones B" en el humedal del Paraná inferior. Arqueología en las Pampas. Editado por C. Bayón, A. Pupio, M. I. González, N. Flegenheimer y M. Frère, tomo I: 325-342. Buenos Aires.

2010a. Explorando la variabilidad de la tecnología ósea a lo largo de la cuenca inferior del río Paraná. Pesquisas, Antropología 68: 133-162.

2010b. Nuevos aportes a la tecnología ósea de la cuenca inferior del río Paraná (Bajíos Ribereños meridionales, Argentina).Arqueología Iberoamericana 8: 21-51.

2010c. Bone Bi-points: Testing Functional Hypothesis. Editado por A. Legrand-Pineau, I. Sidéra, N. Buc, E. David y V. Scheinsohn, Ancient and Modern Bone Artifacts from America to Russia. Cultural, technological and functional signature. BAR International Series 2136: 217-225. 2011. Experimental Series and Use-Wear in Bone Tools. Journal of Archaeological Science 38: 546-557.

Buc, N. y D. Loponte.

2007. Bone tool types and microwear patterns: Some examples from the Pampa region, South America. Editado por C. Gates St-Pierre y R. B. Walker. Bones as Tools: Current Methods and Interpretations in Worked Bone Studies. BAR International Series, 1622: 143-157.

Buc, N. y L. Pérez Jimeno.

2010. Puntas para la comparación. Tecnología ósea en el Paraná Inferior y Medio. Editado por M. A. Gutiérrez, M. De Nigris, P. M. Fernández, M. Giardina, A. F.Gil, A. Gil, A. Izeta, G. Neme y H. D. Yacobaccio), Zooarqueología a principios del siglo XXI: aportes teóricos, metodológicos y casos de estudio, pp. 439-451. Ediciones del Espinillo. Buenos Aires.

Buc, N, y R. Silvestre.

2010. distribución de artefactos líticos y óseos en el humedal del Paraná inferior. Relacionando conjuntos del norte y sur del Paraná Guazú. Arqueología de cazadores - recolectores en la Cuenca del Plata. Editado por G. Cocco y M. R. FeuilletTerzaghi, pp. 171-190. Santa Fe.

Buc, N.; R. Silvestre y D. Loponte.

2010. What about shells? Analysis of shell and lithic cut-marks.The case of Paraná's wetland, Argentina. Not only food: Marine terrestrial and freshwater mollusks in archaeological sites. MUNIBE 31: 252-261. Donostia, San Sebastián. 
Burkart, R., N. Bárbaro, R. Sánchez, y D. Gómez.

1999. Eco-regiones de la Argentina. Administración de Parques Nacionales. Programa de Desarrollo Institucional Ambiental. Secretaría de Recursos Naturales y Desarrollo Sustentable.

Burleigh, R. y M. P. Kerney.

1982. Some chronological implications of a fossil molluscan assemblage from a Neolithic site at Brook, Kent, England. Journal of Archeological Science 9: 29-38.

Buttler, V.

2000. Resource depression on the Northwest Coast ofNorth America. Antiquity 74: 649-661.

Cabrera, L. y E. Zardini.

1978. Manual de la Flora de los Alrededores de Buenos Aires. 2a . Edición. Editorial ACME, Buenos Aires.

Caggiano, M. A.

1977. Contribución a la arqueología del Delta del Paraná. Obra del Centenario del Museo de la Plata 2: 301-324. La Plata.

Caggiano, M. A.

1984. Prehistoria del NE. Argentino. Sus vinculaciones con la República Oriental del Uruguay y Sur de Brasil. Pesquisas, Antropología 38, 117 págs. Instituto Anchietano de Pesquisas. Río Grande do Sul.

Cannon, M. D.

2003. A model of central place forager prey choice and an application to faunal remains from the Mimbres Valley, New Mexico. Journal of Anthropological Archaeology 22: 1-25.

Cavallotto, J. L., 1996. Estratigrafía del Holoceno de la Llanura costera del margen sur del Río de la Plata. Actas del XIII ${ }^{\circ}$ Congreso Geológico Argentino y III Congreso de Exploración de Hidrocarburos, 4: 51- 68, Buenos Aires.

Cavallotto, J. L., R. A. Violante y C. Ferrán.

2005. Evolución y cambios ambientales de la llanura costera de la cabecera del Río de la Plata. Revista de la Asociación Geológica Argentina 60 (2): 353-367.

Cavallotto, J. L., R. A. Violante y H. G. Nami

2002. Late-Pleistocene/Holocene paleogeography and coastal evolution at the mouth of the Río de la Plata: Implications for dispersal of paleoindian people in South America. Current Research in the Pleistocene 19: 13-16.

Cavallotto, J.L., Violante, R.A y Parker, G., 1999. Historia evolutiva del Río de la Plata durante el Holoceno. Actas XIV Congreso Geológico Argentino, pp. 508-511, Salta.

Cavallotto, J. L., R. Violante y G. Parker.

2004. Sea-level fluctuations during the last $8600 \mathrm{yr}$ in the de la Plata River (Argentina). Quaternary International 114: 155-165. 
Cione, A. y E. Tonni.

1978. Paleoethnozoological context of a site of Las Lechiguanas islands, Parana Delta, Argentina. El Dorado.A Newsletter Bulletin on South American Anthropology III (1): 76-86

Cook, K. H. y E. K. Vizy.

2006. South American climate during the Last Glacial Maximum: Delayed onset of the South American monsoon. Journal of Geophysical Research 111, D02110, doi: 10.1029/2005JD005980.

Coll, M.

2011. Análisis de la tecnofactura del material cerámico arqueológico del sitio "Playa Mansa" (provincia de Santa Fe). Resultados preliminares. Avances y Perspectivas en la Arqueología del Nordeste. Editado por M. R. Feuillet Terzaghi, M. B. Colasurdo, J. Sartori y S. Escudero, pp. 69 - 85.

Culleton, B.

2006. Implications of a freshwater radiocarbon reservoir correction for the timing of late Holocene Settlement of the Elk Hills, Kern County, California. Journal of Archaeological Science 33: 1331 - 1339.

Deevey Jr., E. S., M.S. Gross, G. E. Hutchinson y H. L. Kraybill.

1954. The natural $\mathrm{C}^{14}$ contents of materials from hard-water lakes. Proceedings of the National Academy of Sciences, 40: 285 - 288.

Droop, R.

1915. Archaeological Excavation. Cambridge University Press. Cambridge.

Feuillet Terzaghi, M. R.

2008. El Registro Arqueológico del uso del Espacio en la Cuenca Inferior del Río Salado Provincia de Santa $\mathrm{Fe}$. Tesis Doctoral inédita. Facultad de Humanidades y Arte, Universidad Nacional de Rosario.

Figini, A., J. Rabassa, E. P. Tonni, R. Huarte, G. Gómez, J. Carbonari, A. Zubiaga. 1989. Datación radiocarbónica de gasterópodos terrestres en sedimentos del Pleistoceno superior y Holoceno del valle del río Sauce Grande, prov. de Buenos Aires. Actas de las Primeras Jornadas Geológicas Bonaerenses: 809-824.

Fischer, A. y J. Heinemeier.

2003. Freshwater reservoir effect in ${ }^{14} \mathrm{C}$ dates of food residue on pottery. Radiocarbon 45 (3): 449 - 466.

Frontini, R. y M. Picasso.

2010. Aprovechamiento de Rhea americana en la localidad arqueológica El Guanaco. Editado por. M. A. Gutiérrez, M. De Nigris, P. M. Fernández, M. Giardina, A. F.Gil, A. Gil, A. Izeta, G. Neme y H. D. Yacobaccio), Zooarqueologíaaprincipios del siglo XXI: aportes teóricos, metodológicos y casos de estudio, pp. 563-574. Ediciones del Espinillo. Buenos Aires.

Fucks, E., M., Aguirre y C. Deschamps.

2005. Late Quaternary Continental and Marine Sediments of Northeastern Buenos Aires province (Argentina): Fossil Content And Palaeoenvironmental Interpretation. Journal of South American Earth Sciences 20: 45-54. 
Gasparini, G.M, y E. Soibelzon, E.

2003. Primer registro de Tayassu pecari Link, 1795 (Mammalia, Artiodactyla) en la provincia de Buenos Aires. XVIII. Resúmenes de las I Jornadas Argentinas de Mastozoología: 31.

Geyh, M. A., U. Schotterer y M. Grosjean.

1998. Temporal changes of the ${ }^{14} \mathrm{C}$ reservoir in lakes. Radiocarbon 40 (2): 921 - 933.

Gillespie, R., D. Fink, F. Petchey y G. Jacobsen.

2009. Murray-Darling basin freshwater shells: riverine reservoir effect. Archaeology in Oceania 44: 107-111.

Godwin, $\mathrm{H}$.

1951. Comments on radiocarbon dating for samples from the British Isles. American Journal of Science 249: 301 - 307.

Goodfriend, G. A. y D. G. Hood, 1983. Carbon isotope analysis of land snail shells: implications for carbon sources and radiocarbon dating. Radiocarbon 25: 810-830.

Hamblin, W. K.

1978. The Earth's Dynamic Systems, A Textbook in Physical Geology. Burgess Publishing Company, Minneapolis.

Harris, E. C.

1989. Principles of Archaeological Stratigraphy.Academic.Londres.

Houston, R. S., H. Toots y J. C. Kelley.

1966. Iron content of fossil bones of Tertiary age in Wyoming correlated with climatic change. University of Wyoming Contributions to Geology 5: 1-18.

Jackson, T. L., L.A. Shapiro y J.H. King. 1999. Prehistoric Archaeological Resources Inventory and Evaluation at Naval Petroleum Reserve No. 1 (Elk Hills), Kern County, California. Pacific Legacy, Incorporated, Santa Cruz, California.

Kelly, R. L. y L. C. Todd.

1988. Coming into the country: Early paleoindian hunting and mobility. American Antiquity 53 (2): 231-244.

Lafón. C. T.

1971. Introducción a la arqueología del Nordeste argentino. Relaciones V (2): 119152.

Lanzelotti, S., G. Politis, E. Caronari, R. Huarte y J. Bonaparte.

2011. Aportes a la cronología del Sitio 1 de Cañada Honda (partido de Baradero, provincia de Buenos Aires). Intersecciones en Antropología. 12: 355-361.

López, H., C. Morgan y M. Montenegro.

2002. Ichthyological ecoregions of Argentina. Probiota, Serie Documentos 1. Edición digital. Facultad de Ciencias Naturales y Museo, Universidad Nacional de La Plata, 59 pp. La Plata. 
Loponte, D.

1996-98. Arqueología, etnohistoria y estado sanitario de L. guanicoe (Mammalia, Artiodactyla, Camelidae) en la Pampa Ondulada. Palimpsesto, Revista de Arqueología 5: 41-65. Buenos Aires.

Loponte, D.

2004. Atlas Osteológico de Blastocerus dichotomus (ciervo de los pantanos). Editorial Los Argonautas, Buenos Aires.

Loponte, D.

2008. Arqueología del humedal del Paraná inferior (Bajíos Ribereños meridionales). Serie Monográfica Arqueología de la Cuenca del Plata. Editado por D. Loponte y A. Acosta. Instituto Nacional de Antropología y Pensamiento Latinoamericano. Buenos Aires.

Loponte, D.

2012. Los extremos de la distribución: la llanura pampeana y la provincia de Misiones en la arqueología del nordeste. Anuario de Arqueología 4: 39-72.

Loponte, D. y A. Acosta

2004. Late Holocene hunter-gatherers from the Pampean wetlands, Argentina.Zooarchaeology of South America. Editado por G. MengoniGoñalons, pp. 39-57. BAR, International Series. Oxford

2007. Horticultores amazónicos en el humedal del Paraná Inferior: Los primeros datos isotópicos de la dieta. Arqueología de las Pampas. Editado por C. Bayón, A. Pupio, M. I González, N. Flegenheimer y M. Frere, tomo I: 75-93. Sociedad Argentina de Antropología. 2008a. Prólogo. Entre la Tierra y el Agua; Arqueología de humedales de Sudamérica. Editado por. D. Loponte y A. Acosta. Amigos del Instituto Nacional de Antropología y Pensamiento Latinoamericano, pp. I-IV. Buenos Aires.

2008b. El registro arqueológico del tramo final de la cuenca del Plata. Entre la Tierra y el Agua; Arqueología de humedales de Sudamérica. Editado por D. Loponte y A. Acosta, Amigos del Instituto Nacional de Antropología y Pensamiento Latinoamericano, pp. 125-164. Buenos Aires.

Loponte, D., A. Acosta y J. Musali

2004.Complejidad social: cazadores-recolectores y horticultores en la región pampeana. Editado por G. Martínez, M. A. Gutierrez, R. Curtoni, M. Berón y P. Madrid, Aproximaciones Contemporáneas a la Arqueología Pampeana. Perspectivas Teóricas, Metodológicas, Analíticas y Casos de Estudio, pp. 41-60. UNCPBA, Olavarría.

2009.Lo aparente y lo real: la identificación de cuerpos vertebrales a través del uso de los rayos X en los conjuntos icitioarqueológicos pampeanos. Problemáticas de la Arqueología Contemporánea, III: 561-563. Río Cuarto.

2010b. Allometric parameters of Pterodoras granulosus (Valenciennes 1833) and its application to fossil assemblages. International Journal of Osteoarchaeology, 21: n/a. doi: 10.1002/ oa.1200.

Loponte, D., A. Acosta y P. Tchilinguirián.

2010a. Avances en la arqueología de la Pampa Ondulada: sitios Hunter y Meguay. Arqueología Argentina en el Bicentenario de la Revolución de Mayo. Editado por J. R. Bárcena y H. Chiavaza, tomo V: 1811-1826. Zeta Editores, Mendoza. 
Loponte, D. y N. Buc

2011. Don't smash those bones! Anatomical representation and bone tool manufacture in the Pampean region (Argentina, South America). Bones for Tools, Tools For Bones: The Interrelationship of Lithic and Bone Raw Materials. Editadopor K. Seetah y B. Gravina,pp: 35-47. McDonald Institute Monograph Series, McDonald Institute for Archaeological Research, University of Cambridge.

Loponte, D. y L. Kozameh

2010. Nuevos datos para el conocimiento de las dietas prehispánicas del Delta Superior. Comechingonia 13: 115-118.

Loponte, D., R. Sacur Silvestre y P. Tchilinguirián.

2011. Caracterización de afloramientos de calizas silicificadas de la provincia de Entre Ríos (Argentina) y su vinculación con los circuitos de abastecimiento prehispánico. Avances y perspectivas en la arqueología del Nordeste. Editado por M. R. FeuilletTerzaghi, M. Belén Colasurdo, J. I. Sartori y S. Escudero, pp. 125-140.

Lothrop, S.

1932. Indians of the Paraná Delta River. Annals of the New York Academy of Sciences XXXIII: 77-232. New York.

Lyman, R. L.

2003. The influence of time averaging and space averaging on the application of foraging theory in zooarchaeology. Journal of Archaeological Science. 30: 595-610.

Mazza, B.

2010. Avances en el conocimiento de los entierros secundarios del humedal del Paraná inferior. Arqueología Argentina en el Bicentenario de la Revolución de Mayo. Editado por J. R. Bárcena y H. Chiavazza, tomo II, pp. 665-669. Zeta Editores. Mendoza.

Mazza, B. y D. Loponte.

2011. Dimorfismo sexual en poblaciones cazadoras-recolectoras del Paraná inferior. Libro de resúmenes de las Décimas Jornadas Nacionales de Antropología Biológica. Asociación de Antropología Biológica. Edición digital. City Bell.

Mazza, B. y D. Loponte

2012. Las prácticas mortuorias en el humedal del Paraná inferior. Arqueología Iberoamericana 13: 3-21.

MengoniGoñalons, G.

1999. Cazadores de Guanacos de la Estepa Patagónica. Sociedad Argentina de Antropología, Buenos Aires.

Mucciolo, L.

2007. Patrones de explotación y procesamiento de ungulados en el sitio Arroyo Fredes. Arqueología en las Pampas (eds. C. Bayón, M. Isabel González y A. Pupio), pp. 591-614. Sociedad Argentina de Antropología, Buenos Aires. 
Musali, J.

2010. El rol de la pesca entre los grupos humanos de la Baja Cuenca del Plata. Ictioarqueología de conjuntos prehispánicos del Holoceno tardío en el humedal del río Paraná inferior. Tesis doctoral inédita. Facultad de Filosofía y Letras, Universidad de Buenos Aires.

Musali, J. y N. Buc.

2009. La tecnología ósea vinculada a la pesca entre los grupos prehispánicos que habitaron el humedal del río Paraná inferior. Armas prehispánicas: Múltiples enfoques para su estudio en Sudamérica. Editado por J. Martínez y D. Bozzuto. En prensa.

Oldani, N.

1990. Variaciones de la abundancia de peces del valle del río Paraná. Rev. D’Hydrobiologie tropical 23 (1) 90: 67-76.

Orians, G. H. y N. E. Pearson.

1979. On the theory of central place foraging. Analysis of Ecological Systems. Editado por D. J. Horn, R. D. Mitchell y G. R. Stairs, pp. 154-177. The Ohio State UniversityPress, Columbus.

Ottalagano, F.

2007. Análisis contextual del registro artístico del sitio A. Arenal 1 (Provincia de Entre Ríos, Argentina): aportes para el estudio de los aspectos identitarios de los grupos humanos del litoral fluvial del Paraná. Editado por A. Izeta. La Cerámica Arqueológica en la Materialización de la Sociedad. Transformaciones, Metáforas y Reproducción Social. South American Archaeology Series 14: 125-140.

Ottalagano, F. y M. Pérez.

2012. Estudios petrográficos comparativos: un acercamiento regional a la tecnología cerámica del Delta del Paraná. Trabajo enviado para su publicación al I Congreso Internacional de Arqueología de la Cuenca del Plata, Buenos Aires.

Paleo, C. y M. Pérez Meroni.

2004. Problemáticas vinculadas a las estrategias de subsistencia de la Localidad Arqueológica Barrio San Clemente. Editado por C. Gradín y F. Oliva.La Región Pampeana, su pasado arqueológico, pp: 311-319. Editorial Laborde, Buenos Aires.

2007. Primeros Resultados del Sitio "Las Marías", Partido de Magdalena, Provincia de Buenos Aires. Arqueología Argentina en los inicios de un Nuevo Siglo V: 275-283. Rosario.

Parisi, F. y J. Liotta.

2008. Consumo de moluscos bivalvos (Diplodonsp.) en el sitio Cerro Lutz, planicies inundables del humedal del Paraná Inferior. Arqueología Argentina en el Bicentenario de la Revolución de Mayo. J. (eds. R. Barcena y H. Chiavazza), pp. 1793 - 1797. Zeta Editores. Mendoza.

Pérez, M., A. Andrade, G. Leiva y L. Malec.

2011. Propuesta metodológica para el estudio del consumo de recursos vegetales a través del análisis de los gránulos de almidón. Las manos en la masa. Arqueologías y antropologías de la alimentación en Suramérica. Museo de Antropología, Facultad de Filosofía y Humanidades, Universidad Nacional de Córdoba. En prensa. 
Pérez, M. y L. Cañardo

2004. Producción y uso de cerámica en el norte de la provincia de Buenos Aires. Aproximaciones Contemporáneas a la Arqueología Pampeana. Perspectivas teóricas, metodológicas, analíticas y casos de estudio. Editado por G. Martínez, M. Gutiérrez, R. Curtoni, M. Berón y P. Madrid, pp. 335-347. Facultad de Ciencias Sociales, UNCPBA, Olavarría.

Pérez, M. y T. Montenegro

2009. Análisis petrográfico en alfarería del norte de la provincia de Buenos Aires. Problemáticas de la Arqueología Contemporánea (eds.A. Austral y M. Tamagnini),tomo III, pp. 565-573. Facultad de Ciencias Humanas, Universidad Nacional de Río Cuarto, Córdoba.

Pérez Jimeno, L.

2001 Análisis Arqueofaunístico del sitio Barrancas del Paranacito. Florencia, Departamento General Obligado. Provincia de Santa Fe. Revista Arqueología de la Sección Prehistórica, pp.175201. Buenos Aires.

2007. Investigaciones arqueológicas en el sector septentrional de la llanura aluvial del Paraná -margen santafesina-: La variabilidad del registro arqueológico. Tesis Doctoral inédita. Facultad de Ciencias Naturales y Museo, Universidad Nacional de La Plata.

Pérez Jimeno, L. y N. Buc.

2010. Tecnología ósea en la Cuenca del Paraná. Integrando los conjuntos arqueológicos del tramo medio e inferior. MamülMapu: pasado y presente desde la arqueología pampeana. Editado por M. Berón, L. Luna, M. Bonomo, C. Montalvo, C. Aranda y M. Carrera Aizpitarte, pp. 215-228. Ediciones del Espinillo. Ayacucho.

Politis, G.

1988. Paradigmas, modelos y métodos en la arqueología de la Pampa bonaerense. En Arqueología Contemporánea Argentina. Actualidad y Perspectivas. Colección Estudios Arqueológicos: 59-109. Ediciones Búsqueda. Buenos Aires.

2008. The Pampas and Campos of South America.The Handbook of South America Archaeology. Editado por H. Silverman y W. H. Isbell, pp. 235 - 260. Sprenger. New York.

Politis, G y G. León.

2010. Patrones adaptativos de los cazadores recolectores-pescadores de la margen occidental del Paraná inferior-Plata. Arqueología de cazadores recolectores en la Cuenca del Plata. Editado por G. Cocco y M. R. FeuilletTerzaghi; pp. 63- 86. Santa Fe.

Politis, G. y P. Madrid

2001. Arqueología Pampeana: Estado actual y perspectivas. Historia Argentina Prehispánica. Editado por E.Berberían, tomo II, pp. 737-814. Editorial Brujas. Buenos Aires.

Politis, G. y V. Pedrotta.

2006. Recursos faunísticos y adaptación humana en el este de la región Pampeana durante el Holoceno Tardío: el caso del guanaco (Lama guanicoe). Revista Relaciones de la Sociedad Argentina de Antropología XXXI: 301-336. 
Politis, G., M. Bonomo, C. Castiñeira, y A. Blasi.

2010 Archaeology of the Upper Delta of the Paraná River (Argentina): Mound Construction and Anthropic Landscapes in the Los Tres Cerros locality. Quaternary International. En prensa

Popolizio, E.

2003. El Paraná, un río y su historia geomorfológica. Tesis Doctoral inédita. Universidad del Salvador, Facultad de Filosofía, Historia y Letras, 365 págs. Buenos Aires.

Prieto, A. R., M. A. Blasi, C. G. De Francesco y C. Fernández.

2004. Environmental history since 11,000 yr B.P. of the northeastern Pampas, Argentina from alluvial sequences of Luján River. Quaternary Research 62: 146-161.

Rodríguez, J. A.

2001. Nordeste prehispánico. Editado por E. Berberián y A. Nielsen. Historia Argentina Prehispánica II: 693-736. Editorial Brujas, Córdoba.

Rubin, M. y D.W. Taylor.

1963. Radiocarbon activity of shells from living clams and snails. Science 141: 637

Sacur Silvestre, R., N. Buc, A. Acosta y D. Loponte.

2009. Sistemas de armas estratégias de captura de presas das populações caçadoras-coletoras do Pantanal do rio Paraná inferior (Região Pampiana - Argentina). Anais do XV Congresso da SAB Sociedade de Arqueologia Brasilera (edición digital), Belem-Pará.

Salemme, M.

1987. Paleoetnozoología del Sector Bonaerense de la Región Pampeana. Tesis Doctoral. Facultad de Ciencias Naturales y Museo, Universidad Nacional de La Plata. La Plata.

Santini, M. y L. De Santis.

2011. Investigaciones arqueológicas en la provincia de Chaco (Argentina). En Temas de Arqueología: Estudios Tafonómicos y Zooarqueológicos(II). Compilado por A. Acosta, D. Loponte y L. Mucciolo, pp. 137 -165. Instituto Nacional de Antropología y Pensamiento Latinoamericano, Buenos Aires.

Sartori, J y M B. Colasurdo.

2011. El análisis arqueofaunísticos del sitio Playa Mansa: Nuevas perspectivas. Avances y Perspectivas en la Arqueología del Nordeste. Editado por M. R. FeuilletTerzaghi, M. B. Colasurdo, J. Sartori y S. Escudero, pp. $25-41$.

Scarpa, G. F.

2007. Plantas asociadas a la pesca y a sus recursos por los Indígenas Chorote del Chaco Semiárido (Argentina). Boletín de la Sociedad Argentina de Botánica 41 (3-4): 333 - 345.

Sprechmann, P.,

1978. The Paleoecology and Paleogeography of the Uruguayan Coastal Area During the Neogene and Quaternary. Zitteliana 4: 3-72. 
Stephan, E.

1997. Patterns of chemical change in fossil bones and various states of bone preservation associated with soil conditions. Anthropozoologica 1997: 173-180.

Surovell, $\mathrm{T}$.

2003. The Behavioral Ecology of Folsom Lithic Technology. Tesis Doctoral inédita. Universidad de Arizona, Arizona.

Surovell, T, N. M. Waguespack, J. H. Mayer, M. Kornfeld, y G. C. Frison. 2005. Shallow Site Archaeology: Artifact Dispersal, Stratigraphy, and Radiocarbon Dating at the Barger Gulch Locality B Folsom Site, Middle Park, Colorado. Geoarchaeology (20) 6: 627-649.

Sutton, M. Q. y R.S. Orfila.

2003.A radiocarbon correction factor for freshwater shell for the Lower Kern River/Northern Buena Vista Lake Area, Southern San Joaquin Valley, California. Society for California Archaeology Newsletter 37 (2): 23 - 24.

Tamers, M. A.

1970. Validity of radiocarbon dates on terrestrial snail shells. American Antiquity 35: 94100.

Toledo, M.

2010. Geoarchaeology of the Pleistocene-Holocene transition in NE Pampas: evidence of human presence prior to 13,000 BP, Buenos Aires, Argentina. III Simposio Internacional El Hombre temprano en América. C. Jiménez, J. Serrano Sánchez, A. González-González y F. J. Aguilar (eds.), UNAM, Instituto Nacional de Antropología e Historia (INAH), Museo del Desierto, A.C. pp. 205-238. México.

Tonello, M.S. y A.P. Prieto.

2010. Tendencias climáticas para los pastizales pampeanos durante el Pleistoceno tardíoHoloceno: estimaciones cuantitativas basadas en secuencias polínicas fósiles. Ameghiniana 47 (4): 501-514.

Tonni, E., A. Cione, A. Figini, J. Noriega, A. Carlini y S. Miquel.

2001. Extensión del período árido del Holoceno hasta los siglos X a XII basada en el registro de moluscos terrestres en Entre Ríos (Argentina). Actas del XI Congreso Latinoamericano de Geología y III Congreso Uruguayo. Montevideo, Uruguay. http://naturalis.fcnym.unlp.edu. $\mathrm{ar} / \mathrm{id} /$ ? id=000958, pp. 1-5.

Toots, $\mathrm{H}$.

1963. The chemistry of fossil bones from Wyoming and adjacent status. University of Wyoming Contributions in Geology 2: 69-80.

Torres, L. M.

1911. Los Primitivos Habitantes del Delta del Paraná. Universidad Nacional de La Plata-Biblioteca Centenaria, La Plata. 
Violante, R. y G. Parker.

2004. The post-glacial maximum trangression in the de la Plata River and adjacent continental shelf, Argentina. Quaternary International 114: 167-181.

Zucol A.F. y D. Loponte.

2008. Análisis comparativo metodológico y estudio de la abundancia fitolítica en tártaro de dientes humanos de sitios arqueológicos de la provincia de Buenos Aires, Argentina. Matices Interdisciplinarios en Estudios Fitoliticos y de otros Microfósiles/Interdisciplinary Nuances in Phytolith and other Microfossil Studies. Editado por A. Korstanje y P. Babot, BAR International Series S1870, 9: 39-45. Oxford. 